NBER WORKING PAPER SERIES

THE EFFECTS OF HMOS ON

CONVENTIONAL INSURANCE PREMTUMS:

THEORY AND EVIDENCE

Laurence C. Baker

Kenneth S. Corts

Working Paper 5356

\author{
NATIONAL BUREAU OF ECONOMIC RESEARCH \\ 1050 Massachusetts Avenue \\ Cambridge, MA 02138 \\ November 1995
}

We thank David Cutler, Catherine Wolfram, and the participants in the 1995 Boston University Conference on Industrial Organization in Health Care for helpful comments. We also thank David Cutler for his generous assistance with the data. This paper is part of NBER's research program in Health Care. Any opinions expressed are those of the authors and not those of the National Bureau of Economic Research.

(C) 1995 by Laurence C. Baker and Kenneth S. Corts. All rights reserved. Short sections of text, not to exceed two paragraphs, may be quoted without explicit permission provided that full credit, including $(\mathcal{O}$ notice, is given to the source. 


\title{
THE EFFECTS OF HMOS ON \\ CONVENTIONAL INSURANCE PREMIUMS: \\ THEORY AND EVIDENCE
}

\begin{abstract}
We develop a model of imperfectly competitive insurers that compete with HMOs for consumers who have private information about their health status. We illustrate two conflicting effects of increasing HMO activity on conventional insurance premiums. We term these effects market discipline -- HMO competition may limit the ability of insurers to exercise market power, thus driving prices down -- and market segmentation -- HMOs may skim the healthiest patients, thus driving insurers' costs and prices up. We empirically examine the relative importance of these effects using data from a firm-level survey that provides data on premiums, together with market-level measures of HMO activity. Our results suggest that the market segmentation effect is important, and that increases in HMO activity may increase insurance premiums.
\end{abstract}

Laurence C. Baker

Department of Health Research and Policy

HRP Redwood Building, Room 253

Stanford University School of Medicine

Stanford, CA 94305-5092

and NBER
Kenneth S. Corts

Morgan Hall 241

Harvard Business School

Boston, MA 02163 


\section{Introduction}

Driven in part by increases in the activity of Health Maintenance Organizations (HMOs) and other managed care organizations, health care markets are growing increasingly competitive. In many cases, HMOs may be viewed as low-cost competitors to conventional health insurers who provide traditional, fee-for-service, indemnity coverage. If conventional insurers are imperfectly competitive, the entry or expansion of HMOs may lead to reductions in premiums for conventional insurance, as increased competition limits the ability of insurers to exercise market power. HMOs may also segment the market by disproportionately enrolling healthy patients, thereby driving conventional insurers' costs and premiums up. Despite the fact that understanding the ways HMOs interact with conventional insurers is important for evaluating the likely implications of the ongoing shift toward managed care and for evaluating policy proposals that would further encourage the growth of managed care, relatively little attention has been devoted to this issue. In this paper we develop a model of competition between HMOs and conventional health insurers that illustrates the interaction between these markets and emphasizes the competing 'discipline' and 'segmentation' effects. We then use data on conventional insurance premiums from a nationwide 1991 survey of employers, coupled with county-level data on HMO market share, to empirically examine the relationship between HMO activity and conventional premiums.

HMOs have played a role in the U.S. health care system for many years. Much of the growth in HMO activity followed the passage of Federal HMO enabling legislation in 1971, although HMOs existed in some places before then. After 1971, growth was initially slow, but accelerated in the 1980s as health care costs began to rise and HMOs were perceived as a way to contain them. In 1980 , there were 236 HMOs operating in the U.S., with approximately 9.1 million members. By 1994, there were 556 HMOs in operation, with 50 million members. Nationwide, approximately 
$19 \%$ of people with health insurance were enrolled in an HMO in 1994 (GHAA, 1994).

If HMOs enter or expand operations in a market, they may influence the behavior of other non-HMO providers in that market. One important possibility is that the entry or expansion of HMOs in a market increases the level of competition, since HMOs may compete with non-HMO providers or insurers for the business of employers or other purchasers of health insurance (Feldman et al., 1990). By providing a low-priced alternative to conventional insurance, HMOs may limit the price consumers are willing to pay for conventional insurance. Further, as HMO market share increases, conventional insurers may find it optimal to defend their share by cutting prices. Competition could also force non-HMO providers to become more efficient in production by, for example, changing the ways in which they provide care or expanding utilization review efforts. If non-HMO insurers or providers earn excess profits in the absence of HMOs, increasing the level of competition could limit their ability to exercise market power and therefore lead to lower prices. We term this effect of HMOs on conventional insurers the "market discipline effect."

HMOs may also influence the type of product provided by conventional insurers. For example, in the absence of competition, many conventional insurers paid relatively little attention to hospitalization rates or the lengths of hospital stays. When faced with competition, however, they may impose utilization review or other oversight mechanisms designed to limit utilization of hospitals and other costly services (see, e.g., Goldberg and Greenberg, 1979; Frank and Welch, 1985; Feldman and Dowd, 1986). This may also lead to changes in premiums.

In addition to these competitive effects, HMOs may affect non-HMO providers by inducing biased selection in the market. Several studies have found that HMOs tend to receive a disproportionate share of healthy patients (Eggers and Prihoda, 1982; Brown et al., 1986; Wilensky and Rossiter, 1986; Hellinger, 1987; Brown, 1988; Hill and Brown, 1990; Riley et al., 1991; Hill and 
Brown, 1992; Hill et al., 1992; Lichtenstein et al., 1992; Brown et al., 1993). This may occur for a variety of reasons. HMOs emphasize primary and preventive care, which may be particularly appealing to healthy individuals. HMOs may also limit the use of expensive tests and procedures, which may be particularly unappealing to less healthy individuals. In addition, joining an HMO often means switching providers, a prospect that may be less attractive to relatively unhealthy patients who are likely to have built strong relationships with their providers. If healthier patients tend to enroll in HMOs, premiums charged by conventional insurers may increase because the cost of caring for the remaining, less healthy, patients rises. We term this effect the "market segmentation effect."

In Section 2, we demonstrate the existence of these opposing forces in a simple model of imperfectly competitive conventional insurers competing against HMOs for the business of consumers who have private information about their health status. We begin by examining only the market discipline and segmentation effects, and then augment the model so that it also encompasses changes in plan characteristics. There are, of course, other ways in which HMOs may affect conventional providers and insurers. For example, HMOs could influence non-HMO expenditures by influencing the environment in which non-HMO providers operate. By affecting the availability of medical technologies, for example, HMOs may alter the set of treatment options open to nonHMO providers, and thus affect their practice patterns. HMOs could also affect practice patterns through learning effects. If, as some models of physician learning (e.g. Phelps, 1992) suggest, physicians tend to adopt the practice patterns of other physicians around them, then increases in the number of HMO physicians in a given area may result in faster promulgation of conservative practice techniques there. Nonetheless, we suspect that the market discipline and market segmentation effects are the most important ways that HMOs influence conventional insurers, and 
begin our modelling effort there.

Following development of the model, we empirically examine the effect of HMOs on conventional premiums using data from a 1991 nationwide survey of firms, coupled with nationwide county-level data on HMO activity. We use IV models to correct for simultaneous determination of premiums and market share, unobserved patient preferences, and possible measurement error in the estimates of HMO activity. We find limited evidence that premiums are convex in market share and are increasing above market shares of 10-13 percent. This is consistent with a situation where, for sufficiently high market shares, the market segmentation effect of HMOs dominates the market discipline effect. Sections 3 and 4 describe the data and estimation.

We are aware of no previous efforts to build models of the type examined here. Some investigators have examined competition among HMOs (e.g., Encinosa and Sappington, 1995) but have not considered the interaction between HMOs and conventional insurers. Feldman and Dowd $(1982,1991)$ examined the effect of adverse selection on conventional premiums in a graphical model that has some features in common with our model, but did not consider market discipline or quality effects. Other papers have also examined adverse selection in detail, but have not addressed it in the present context (e.g. Lewis and Sappington, 1995; Marquis, 1992; Newhouse, 1984; Pauly, 1984; Van de Ven and Van Vliet, 1995). There is also a substantial, if inconclusive, empirical literature on the existence and significance of so-called "spillover effects" of HMOs on non-HMO health care utilization and costs. Several studies have supported the hypothesis that HMOs may reduce costs in other sectors of the health care market (Goldberg and Greenberg, 1979; Frank and Welch, 1985; Dowd, 1987; Noether, 1988; Robinson, 1991; Clement et al., 1992; Welch, 1994; Baker, 1995b). On the other hand, some studies have failed to find evidence of spillovers (Feldman et al., 1986; Luft et al., 1986; McLaughlin, 1988). However, most of these studies have either 
examined the relationship between HMO market share and hospital expenditures, or have been focused on narrow sets of markets. Only one study examined the relationship between HMO activity and conventional insurance premiums. Feldstein and Wickizer (1993) examined the 19851991 premium growth rates of 95 insured groups covered by a single carrier. They found that increases in HMO market share were negatively associated with premium growth rates. That study suggests that HMOs may have a negative effect on conventional premiums, but the fact that it is limited to a small number of firms covered by a single carrier limits its generalizability.

\section{A Model of an Imperfectly Competitive Health Care Market}

We take the existence and characteristics of two types of health care plans, HMOs and conventional insurance, to be exogenous and fixed. Each type of plan $k=h, i$ (denoting HMO and conventional insurance coverage, respectively) requires a premium $\mathrm{p}_{\mathrm{k}}$. The plans yield "benefits" (the measured value of the treatment provided) $b_{k}(x)$ for each realization of a consumer's health state $x$, and require out-of-pocket payments $s_{k}\left(b_{k}(x)\right) .{ }^{\prime}$ We assume each consumer's utility function is separable in benefits and payments, so that $U\left(b_{k}(x), x, k ; \gamma\right)-s_{k}\left(b_{k}(x)\right)-p_{k}$ is the net utility derived from enrollment in plan $k$ when health state $x$ is realized. The inclusion of $k$ in addition to $b_{k}(x)$ permits consumers to value the plans' coverage differently even when measured benefits are identical. The parameter $\gamma$ indexes the importance of such effects, with higher values of $\gamma$ indicating a more favorable assessment of HMO coverage by consumers. Health care consumers have private information about their health status $\theta$, which is distributed as $F(\theta)$. Health status determines the distribution of health states $x$, denoted by $G(x \mid \theta)$. Higher values of $x$ are assumed to represent poorer

'Note that $s_{\mathbf{k}}$ represents a simple copayment if $s_{k}(z)=\eta z$. More complicated functions easily capture deductibles, variable copayments, and out-of-pocket caps in the context of this model. 
health states, and increases in $\theta$ correspond to decreases in health status in the sense that $G\left(x \mid \theta_{2}\right)$ first-order stochastically dominates $\mathrm{G}\left(\mathrm{x} \mid \boldsymbol{\theta}_{1}\right)$ if and only if $\boldsymbol{\theta}_{2}>\theta_{1}$. For example, in a simple two-state model where health and illness are denoted $x=0$ and $x=1$ respectively, $\theta \in[0,1]$ might represent the probability of illness.

A single measure of the plans' benefits is sufficient for the model we develop. Define the differential expected net benefit $B$ for a patient of type $\theta$ by

$$
B(\theta ; \gamma)=E_{G(x \mid \theta)}\left[U\left(b_{i}(x), x, i ; \gamma\right)-s_{i}\left(b_{i}(x)\right)\right]-E_{G(x ; \theta)}\left[U\left(b_{h}(x), x, h ; \gamma\right)-s_{h}\left(b_{h}(x)\right)\right] \text {, }
$$

where $E_{G(x \mid \theta)}$ denotes the expectation over health states $x$ of the bracketed term with respect to $G(x \mid \theta)$. We make our assumptions about consumer preferences (and implicitly about the relative benefit and copayment structures of the plans) directly on this function B. Specifically, we assume that B is increasing in $\theta$ (denoted $\mathrm{B}^{\prime}>0$ throughout) and that $\partial \mathrm{B}^{\prime} / \partial \gamma$ is negative. That $\mathrm{B}$ is increasing in $\theta$ indicates that less healthy types have a stronger preference for conventional insurance, perhaps because the difference in benefits is greater in poorer health states, which are for them more likely. It will become clear that $\mathrm{B}^{\prime}$ indexes the substitutability of plans, with larger $\mathrm{B}^{\prime}$ indicating that the plans are poorer substitutes in the sense that HMOs must offer a larger price discount to induce a given number of consumers to switch to HMOs. The assumption that $\mathrm{B}^{\prime}$ is decreasing in $\gamma$ is simply a matter of convention concerning the parameterization of consumers' common evaluation of the relative benefits of HMOs and traditional insurance. The assumption that $\partial \mathrm{B}^{\prime} / \partial \gamma$ is negative implies that the differential benefit increases less quickly in health status $\theta$ when HMO coverage is more highly valued by consumers. This implies that when consumers value HMO coverage more highly ( $\gamma$ large), the plans are better substitutes (B' small). In general, these assumptions hold if, as health states worsen, increases in conventional insurance benefits sufficiently outpace increases in HMO 
benefits. $^{2}$

For any set of premiums for traditional insurance and HMO plans, patients self-select into the two plans by comparing the premium differential $p_{i}-p_{h}$ with the differential expected net benefit. Some consumer type $\theta_{0}$ will be just indifferent between the two plans, where $\theta_{0}$ is defined implicitly by:

$$
B\left(\theta_{0} ; \gamma\right)=p_{i}-p_{h}
$$

Since $B(\theta ; \gamma)$ is increasing in $\theta$, all types $\theta<\theta_{0}$ will choose the HMO plan and all types $\theta>\theta_{0}$ will choose traditional insurance. ${ }^{3}$ Therefore, HMO penetration (the fraction of the population enrolled in HMOs) is given by $\phi\left(p_{i}, p_{h}\right)=F\left(\theta_{0}\right)$, where the functional dependence of $\theta_{0}$ on prices is implicit.

${ }^{2}$ If the plans have identical benefit, deductible, and copayment structures $\left(b_{i}(x)=b_{h}(x)=b(x)\right.$ for all health states $x$, and $\left.s_{i}(z)=s_{h}(z)=s(z)\right)$, these properties of $B(\theta ; \gamma)$ hold if $\gamma U(z, x, i ; \gamma)=U(z, x, h ; \gamma)$ for $\gamma \in(0,1)$. In practice, we expect $b_{i}^{\prime}(x)>b_{h}{ }^{\prime}(x)$ over a large range of health states; because of the prevalence of deductibles in traditional insurance plans, we expect $s_{i}^{\prime}(z)>s_{h}{ }^{\prime}(z)$ at low spending levels and $s_{i}^{\prime}(z)<s_{h}^{\prime}(z)$ at high spending levels. This indicates that our conditions are very likely to hold at high spending levels, but that the presence of large copayments (perhaps of $100 \%$ ) below the conventional insurance deductible may significantly reduce the net differential benefit at low spending levels. Our conditions hold universally either if the conventional insurance benefit exceeds the $\mathrm{HMO}$ benefit by enough to offset the high conventional insurance copayment at levels below the deductible or if $G(x \mid \theta)$ places enough weight on poor health states for all $\theta$. Technically, given the stochastic dominance condition, a sufficient condition for $B^{\prime}>0$ is that $\left[U_{1}\left(b_{i}(x), x, i ; \gamma\right)-s_{i}{ }^{\prime}\right] b_{i}^{\prime}-\left[U_{1}\left(b_{h}(x), x, h ; \gamma\right)-s_{h}{ }^{\prime}\right] b_{h}{ }_{h}>0$, where $U_{1}$ indicates the partial derivative of $U$ with respect to its first argument (see Lemma 2 in Corts (1993)). Given $B^{\prime}>0$, the assumption that $\partial B^{\prime} / \partial \gamma<0$ holds, for example, if $\gamma U(z, x, i ; \gamma)=U(z, x, h ; \gamma)$ for $\gamma \in(0,1)$. Note that for the reasons mentioned, $\left[U_{1}\left(b_{k}(x), x, k ; \gamma\right)-s_{k}{ }^{\prime}\right]$ is likely to be smaller for the insurance plan at low values of $x$, though positive for both insurers and HMOs for all $x$. The above inequality makes clear that our conditions hold for $b_{i}{ }^{\prime}$ sufficiently larger than $b_{h}{ }^{\prime}$.

${ }^{3}$ While previous literature leads us to believe that the degree of preference for HMOs is increasing in $\theta$ on average, we recognize that this does not necessarily lead to perfect segmentation of the market. For example, if patient preference for HMOs is a function of distances to the nearest HMO and non-HMO provider, as well as $\theta$, then a sicker patient who lives near HMO providers may prefer HMO coverage despite his or her poor health, while a healthier patient who lives near non-HMO providers may prefer conventional insurance. Our model precludes this possibility since consumers are assumed to vary only in health status. If $\mathrm{B}(\theta ; \gamma)$ included patient-specific preference variables to account for this possibility, the condition $\mathrm{B}^{\prime}>0$ would require that poorer health increases the differential net benefit on the margin, or that, ceteris paribus, less healthy patients tend to be willing to pay a larger premium to avoid HMO enrollment. Unless these patient-specific factors affecting HMO preference are systematically correlated with health status, this distinction is irrelevant. 
This function $\phi\left(\mathrm{p}_{\mathrm{i}}, \mathrm{p}_{\mathrm{h}}\right)$ can be thought of as the demand function for health care plans.

To fully define our model of the conventional insurance market, we must consider the determination of supply in addition to the demand model outlined above. We begin by defining marginal cost as the expected value of the variable costs incurred (net of copayments) in providing the defined benefit to the marginal consumer. The marginal cost to a firm of type $k$ of serving consumer type $\theta$ is denoted $c_{k}(\theta)$. Since higher $\theta$ types are less healthy, it is natural to assume $c_{k}{ }^{\prime}(\theta)>0$ for $k=i, h$.

We wish to explore the possibility that competition among HMOs has a disciplining effect on conventional insurers, and a necessary condition for this effect to arise is that conventional insurers are imperfectly competitive. For simplicity, we assume that the oligopolistic competition in the insurance market can be modeled as a symmetric Cournot game with an exogenous number of firms $\mathrm{N}_{\mathrm{i}}$. Insurers take the HMO industry's price as fixed, then play a Cournot game facing the industry demand function $\phi\left(\mathrm{p}_{i}, \mathrm{p}_{\mathrm{h}}\right)$ defined above. This yields an industry-equilibrium-response function giving the insurance industry's equilibrium price as a function of the HMO industry's price. While the assumption of symmetry is extreme, it allows us to analyze the general comparative statics properties of this model without undue notation. An asymmetric Cournot game yields qualitatively similar comparative statics results.

The industry equilibrium condition for the symmetric Cournot game is:

$$
p_{i}^{*}=c_{i}\left(F^{-1}\left(\phi^{*}\right)\right)+\left[\left(1-\phi^{*}\right) / N_{i}\right] F^{-11}\left(\phi^{*}\right) B^{\prime}\left(F^{-1}\left(\phi^{*}\right) ; \gamma\right)
$$

This is the familiar Cournot supply relation, which shows that prices are equal to marginal cost plus some markup that is increasing in quantity (since $\phi$ is HMO penetration, $1-\phi$ is the insurers' quantity), decreasing in demand elasticity (which is inversely related to $B^{\prime}$ in this model), and decreasing in the number of competitors in the market. These features are what drive the qualitative 
results of the comparative statics analysis that follows; other plausible models of imperfect competition would yield supply relations with similar characteristics and would therefore lead to similar qualitative results. This expression is an industry supply relation; when solved simultaneously with the demand relation derived above and an industry supply relation for the HMO market, it determines equilibrium prices and penetration. We do not model competition in the HMO market explicitly, ${ }^{4}$ but assume that the HMO industry supply relation takes the form $\mathrm{p}_{\mathrm{h}}{ }^{*}=\mathrm{h}\left(\phi^{*} ; \gamma, \alpha\right)$, where $\alpha$ captures the nature of competition in the HMO market. For example, $\alpha$ might measure the number of HMOs or the Herfindahl index for the HMO market.

The purpose of this analysis is to understand the interaction of the HMO and insurance markets when the plans are imperfect substitutes and patient self-selection adversely affects the insurers' customer base. In particular, we want to determine when HMO competition may exert a disciplining effect on conventional insurers, when HMO competition leads to increased market segmentation that drives conventional insurers' costs (and potentially premiums) up, and when each effect is likely to prevail. To this end, we examine the comparative statics properties of the above expression for $\mathrm{p}_{\mathrm{i}}^{*}$ (equation 3 ).

Observation \#1. Increases in equilibrium HMO penetration $\phi^{*}$ may raise or lower insurance premiums $p_{i}^{*}$.

This supply relation illustrates the market segmentation $v s$. market discipline dichotomy well. Differentiation of the supply relation yields

$$
d p_{i}^{*} / d \phi^{*}=\left[c_{i}^{\prime}-B^{\prime} / N_{i}\right] F^{-1}
$$
(1995).

${ }^{4}$ Other authors have considered competition among HMOs. See, e.g., Encinosa and Sappington 
Note that $F^{-11}$ is necessarily positive since $F(\theta)$ is the c.d.f. of $\theta$. To illustrate the major effects as simply as possible, we have assumed that all second-order effects are negligible; in particular, B" and $\mathrm{F}^{-1 "}$ are assumed to be approximately zero. ${ }^{5}$ The first term captures the market segmentation effect. Since healthier consumers self-select into HMOs, increases in the level of HMO penetration lead to a less healthy marginal consumer (the consumer indifferent between insurance and HMO coverage). Since the cost of providing care increases with type $\theta\left(c_{k}{ }^{\prime}>0\right)$, the marginal cost to both HMOs and insurers increases with penetration. The second term captures the market discipline effect. Increases in HMO penetration shrink the insurance market, which makes insurers more willing to sacrifice margin for volume since the population of inframarginal consumers is smaller. This leads to lower price-cost margins for the insurers in equilibrium.

Observation \#2. Other things equal, the market discipline effect is more likely to prevail when insurance and HMO coverage are poorer substitutes ( $B^{\prime}$ is large) and when the insurance market is less competitive ( $N_{i}$ is small). The market segmentation effect is more likely to prevail when $c_{i}^{\prime}$ is large.

When $\mathrm{B}^{\prime}$ is large, the plans are poor substitutes in the sense in that consumers are relatively sWhile we ignore second-order derivatives to simplify our analysis, this is not crucial. The full
derivative $d p_{i}^{*} / d \phi^{*}$ contains two extra terms:
\[ \left(1-\phi^{*}\right) / N_{i} F^{-1 \prime \prime} B^{\prime}+\left(1-\phi^{*}\right) / N_{i} B^{\prime \prime} F^{-11} \text {. } \]
These are second-order market discipline effects, which capture the effect of penetration on price-cost
margins. By focusing on first-order effects, we rule out changes in the substitutability of plans $\left(B^{\prime \prime}=0\right)$
and in the density of the population $\left(\mathrm{F}^{-1 "}=0\right)$ as $\phi^{*}$ changes. This leaves only the effect of quantity, and
the first-order market discipline effect implies that insurance markups decrease in HMO penetration.
However, including these second-order terms demonstrates that the discipline effect could be less
negative, or even positive, if $F^{-1 "}$ or $B^{\prime \prime}$ is positive. When $F^{-1 " 1}$ is positive, increases in $\phi$ lead to decreases
in population density near the marginal consumer $\theta_{0}$, and when $B^{\prime \prime}$ is positive, increases in $\phi$ decrease the
substitutability of the plans. In either case, higher markups arise because given decreases in price attract
fewer consumers (demand becomes less elastic at every price/quantity pair), thus tipping the
margin/volume tradeoff toward higher margins. 
slow to switch plans as the price differential increases. Put another way, when B' is large, HMOs must offer larger price discounts to induce a given number of consumers to enroll in HMOs. Thus, when $\mathrm{B}^{\prime}$ is large and when $\mathrm{N}_{i}$ is small, the insurance market is relatively uncompetitive and margins are high. High margins amplify the importance of defending share when penetration increases, and lead to a larger market discipline effect. When $B^{\prime}$ is small (the products are close substitutes) or $N_{i}$ is large, the insurance market is competitive, prices track marginal costs closely, and the market segmentation effect is more likely to prevail. The slope of $c_{i}^{\prime}$ directly affects the importance of the market segmentation effect. When $c_{i}^{\prime}$ is large, marginal costs are more dramatically affected by the adverse selection problem facing the insurers.

Observation \#3. Increases in HMO penetration driven by changes in preferences $\gamma$ lead to larger reductions (smaller increases) in insurance premiums than equivalent changes in penetration driven by changes in competition in the HMO market.

Observations 2 and 3 address the effect of implicitly exogenous changes in penetration on insurance premiums. However, penetration is endogenous to this model, and equilibrium penetration is determined as the result of competition among and between insurers and HMOs. Within the context of this model, there are two interesting potential sources of variation in penetration: preferences $\gamma$, and the degree of competition in the HMO market $\alpha$. We assume that increases in $\gamma$ and increases in the competitiveness of the HMO market lead to increases in equilibrium HMO penetration $\phi^{*}$. Since $d p_{i}^{*} / d \phi^{*}$ is constant regardless of the source of variation in penetration, the indirect effects of changes in $\gamma$ and $\alpha$ on prices through penetration will be identical. However, while the effect of changes in $\alpha$ is limited to these indirect segmentation and discipline effects that arise through the imperfect substitutability of the two products, changes in $\gamma$ have a 
direct effect on insurance premiums. Differentiation of (3) yields

$$
d p_{i}^{*} / d \gamma=\left[\left(I-\phi^{*}\right) / N_{i} \partial B^{1} / \partial \gamma\right] F^{-11}+d p_{i}^{*} / d \phi^{*} d \phi^{*} / d \gamma
$$

Since $\partial \mathrm{B}^{\prime} / \partial \gamma<0$ by assumption, increases in $\gamma$ tend to lower insurance prices through a direct competitive effect, evident in the first term of equation (5). This direct effect captures the fact that increases in $\gamma$ make the products better substitutes by lowering $\mathbf{B}^{\prime}$. This makes industry demand more elastic, and therefore leads to lower margins in an imperfectly competitive environment. Changes in $\gamma$ also have indirect segmentation and discipline effects through $d \phi^{*} / d \gamma$. A change in HMO competition that leads to a similar change in $\phi^{*}$ has only the indirect effect on insurance premiums through penetration, since $\alpha$ is assumed to affect the HMO market uniquely.

It is natural to assume that increases in the competitiveness of the HMO market drive down HMO prices and expand market share. In fact, we show in Appendix A that $d \phi^{*} / d \alpha>0$ for all parameter values in a simple linear version of this model, where $\alpha$ represents the number of symmetric Cournot competitors in the HMO market. The effect of $\gamma$ on penetration is less clear. The assumption that $d \phi^{*} / d \gamma>0$, which is critical to observation \#3, is intuitively plausible at one level, since increases in $\gamma$ seem to create a more favorable environment for HMOs since their services are valued more highly. In fact, in a simple linear version of this model, it is possible to show that an (arbitrarily small) marginal cost advantage for HMOs relative to conventional insurers is a sufficient condition for HMO penetration to be increasing in $\gamma$ (see Appendix A). However, increases in $\gamma$ increase the substitutability of the plans, thus increasing inter-market competition and lowering equilibrium conventional insurance prices at every level of penetration $\phi$. To the extent that these lower conventional insurance prices reduce HMO profits, they are likely to induce exit. Or put another way, in a cross-sectional sample, more aggressive HMO entry is likely to be observed in markets with less intense price competition, i.e., markets with low $\gamma$. These two conflicting forces 
work to determine the net effect of increases in $\gamma$ on equilibrium penetration when endogenous HMO entry is accounted for. We argue in Appendix B that either of these two forces may dominate, and that as long as increases in $\gamma$ do not induce too much exit through increased inter-market price competition, the assumption that $d \phi^{*} / d_{\gamma}>0$ holds. ${ }^{6}$

\section{Endogenous plan characteristics}

We have thus far taken the characteristics of the two types of plans to be exogenous and assumed competition between the imperfectly substitutable plans to be strictly on the basis of price. The disciplining effect that HMO competition exerts on conventional insurers in such a model is a direct result of the strategic complementarity typical of competition in differentiated goods industries. However, some empirical studies, along with considerable anecdotal evidence, suggest that HMOs may also lead to changes in the patterns of care for non-HMO patients. For example, some studies have shown that conventional insurers react to competition by increasing the level of utilization review and/or employing other oversight mechanisms, thereby reducing hospital utilization and the use of other high-cost services among conventional insurance patients (Goldberg and Greenberg, 1979; Frank and Welch, 1985; Feldman and Dowd, 1986). The model above can be extended to illustrate such an effect, and to show how this phenomenon affects the relative importance of the market segmentation and market discipline effects.

For simplicity of exposition, we continue to take HMO plan characteristics as fixed, but allow some parameter $\mathrm{k}$ characterizing the level of the insurance plans' benefits to vary

${ }^{6}$ Our assumption that $d \phi^{*} / d \gamma>0$ is critical for observation \#3, which is in turn important for our discussion of omitted variable bias in section 4 . We argue here and in the appendices that this condition is plausible and likely. If, however, $d \phi^{*} / d_{\gamma} \ngtr 0$, only observation $\# 3$ is invalid; our other results, both theoretical and empirical, remain valid. 
endogenously. In the simplest case, $x$ might simply scale up the benefit function $b_{i}(x)$. The differential expected net benefit depends on $\kappa$, and is now written $B(\theta ; \gamma, \kappa)$. We assume that reductions in insurance plans' benefits (decreases in $\mathbf{k}$ ) make the two plans better substitutes in the sense that a smaller price differential is required to induce a given fraction of the population to choose the HMO plan: $\partial \mathrm{B}^{\prime} / \partial \mathrm{k}>0$. In addition, the choice of $\mathrm{x}$ affects the insurers' marginal cost, which is now given by $c_{i}(\theta ; k)$. Increases in $k$ are assumed to be costly: $\partial c_{i} / \partial x>0$.

The first order condition determining the optimal price is unchanged. Again taking second order effects to be negligible, totally differentiating the equilibrium supply relation with respect to penetration yields:

$$
d p_{i}^{*} / d \phi^{*}=c_{i}^{\prime} F^{-11}+\partial c_{i} / \partial k d k^{*} / d \phi^{*}+\left\{-B^{\prime} / N_{i}+\left(1-\phi^{*}\right) / N_{i} \partial B^{\prime} / \partial k d k^{*} / d \phi^{*}\right\} F^{-1}
$$

Observation \#4. If increases in HMO penetration lower the level of benefits in conventional insurance plans $\left(d \mathrm{k}^{*} / d \phi^{*}<0\right)$, insurance premiums are more decreasing in penetration $\left(d p_{i}{ }^{*} / d \phi^{*}\right.$ is smaller) than if the level of benefits is fixed.

The first and third terms of this expression capture the same market segmentation and market discipline effects that arise in the model with fixed benefit levels. ${ }^{7}$ However, the second and fourth terms represent two additional effects, both negative, associated with reductions in the level of benefits. The second term captures the obvious fact that reductions in the provision of costly benefits lower the insurers' marginal costs. The fourth term shows that in addition to costs, margins also fall, since decreases in $\mathrm{x}$ increase the demand elasticity (which is inversely related to $\mathrm{B}^{\prime}$ ) by making the plans better substitutes. Increases in the substitutability of the plans lower margins by

${ }^{7}$ We again assume $\mathrm{B}^{11}$ and $\mathrm{F}^{-11}$ are approximately 0 . Exactly the same two terms are omitted from the analysis here as in the model with fixed plan quality (see footnote \#5). 
increasing inter-market competition.

Observation \#5. If increases in HMO penetration lower the level of benefits in conventional

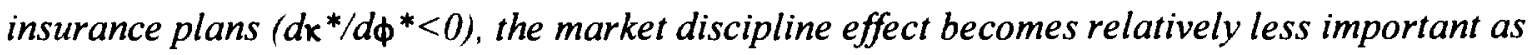
penetration increases, and insurance premiums are a convex function of HMO penetration $\phi^{*}$.

In the absence of second-order effects, the relative importance of the market segmentation and market discipline effects is invariant to HMO penetration when the level of benefits is fixed. As noted in observation \#1, either effect may prevail, but the relative importance of these effects does not vary with $\phi$. As noted in observation \#2, the market discipline effect is more likely to prevail when margins are high, which may result from relatively inelastic demand (high $\mathrm{B}^{\prime}$ ). In the model with variable benefit levels, the benefit-level-reducing effect of increasing HMO penetration tends to lower B', raising demand elasticity and shrinking margins (observation \#4). This implies that the market discipline effect becomes weaker as declining insurance plan benefit levels shrink insurers' margins and reduces their incentives to defend share with aggressive pricing in response to increasing HMO penetration. Formally, the coefficient on $\phi^{*}$ in equation (6) is positive since $\partial \mathrm{B}^{\prime} / \partial \mathrm{x}>0$ and $d \mathrm{x}^{*} / \mathrm{d} \phi^{*}<0$.

\section{Data}

We now turn to an empirical examination of the relationship between HMO activity and conventional insurance premiums. As in the model above, we use HMO market share as our measure of HMO activity. Other measures of HMO competition (e.g. Herfindahl indices) proved difficult to incorporate in practice since they are highly correlated with market shares. This section describes the HMO and firm data that we use. The next section describes the estimation. 


\section{HMO Activity}

The HMO market share data used here were constructed from available data on the enrollment and market share of all HMOs operating in the United States in 1990. The process by which the estimates were constructed is described briefly here; full details are presented in Baker (1995a). Conceptually, construction took place in three steps. First, for each HMO in the United States, the total enrollment and service area, specified by county, were obtained. Second, the enrollment of each HMO was distributed among the counties in its service area. Finally, the total number of enrollees in each county was computed by summing county enrollments over all of the HMOs serving the county. Using the total number of HMO enrollees in each county, HMO market share was computed as the ratio of enrollees to total population.

The primary source of information on HMO enrollments and service areas is the National Directory of HMOs, published annually by the Group Health Association of America (GHAA). Each year the GHAA conducts a mail survey, with telephone follow up, of all known HMOs in the country and, among other things, asks their total enrollment and their service area. The results of the survey are published in the annual Directories. To construct estimates of 1990 county market share, the 1991 Directory, which lists enrollment and service area for each of the 567 HMOs in the mainland U.S., Alaska, and Hawaii as of December 31, 1990, was used. All but one of the HMOs in the directory indicated their enrollment. In the missing case, data from the 1992 Directory was used. Most HMOs (459 of 567) also indicated the counties that they served. However, 108 HMOs (19 percent), did not provide a clear definition of their market area in terms of counties. For these HMOs, market areas were determined by reference to subsequent Directories and/or telephone contact.

The next step was to distribute the enrollment of each HMO among the counties in its service 
area. Initially, this was done by simply distributing enrollment proportionally to county population. In addition, since HMO enrollment may be concentrated near HMO headquarters or since HMOs may locate their headquarters in areas where their enrollment is concentrated, estimates that incorporate both county population and distance from HMO headquarters were constructed. The correlation between estimates produced by the two methods is approximately 0.97 . Estimates that incorporate both population and distance are used in the analyses presented here.

Once enrollments had been distributed over service areas, the total number of enrollees in each county was computed by summing over the set of HMOs serving that county. Using the set of county enrollment estimates, county market share estimates were computed as the proportion of the population enrolled in HMOs. MSA-level market share estimates were computed as the weighted average of the market shares in the constituent counties, where the weight was county population.

Since the county service areas on which these estimates are based are quite accurate, it is likely that the estimates themselves are also quite accurate. Comparisons with limited HMO market share data available from independent sources also suggest that the new estimates are reasonable measures of HMO activity levels (Baker, 1995a).

\section{Firm Data}

Firm data come from the 1991 Health Insurance Association of America (HIAA) survey of firms. The sample includes 3,323 public and private firms that were interviewed in the spring of 1991. Self-employed individuals and federal workers are excluded. The survey had a response rate of 76 percent (Sullivan et al., 1992).

As part of the survey, firms were asked to provide information on the health plans offered to their employees and the premiums associated with these plans. For the most part, the data on health 
insurance plans and premiums represent policies in force for the 1991 calendar year. Specifically, firms were asked whether they offered conventional, HMO, PPO, or point-of-service (POS) plans to their employees. For each plan type offered, they were asked to indicate the premium and other characteristics associated with the particular plan of that type in which the largest number of employees were enrolled. Firms that offered only a single plan of a given type provided information for the plan offered. Firms with more than one plan of a given type provided information for the largest plan of that type. The estimation below uses the monthly premium for single coverage for conventional insurance. Firms were also asked to provide firm characteristics, including the number of employees, age and earnings distribution of employees and the employee turnover rate, and information on the distribution of employees across each of the four plan types.

Of the 3,323 firms surveyed, 2,533 (78 percent) offer some kind of health insurance. Of these, 1,854 (73 percent) offer a conventional policy. Table 1 provides some information on the characteristics of firms in the sample, firms in the sample that offer health insurance, and firms in the sample that offer conventional health insurance. Larger firms and higher-wage firms are, in general, more likely to offer insurance. To construct a sample for analysis, firms that did not offer conventional insurance, failed to report complete information on the survey, or reported a composite conventional premium rather than separate premiums for single and family coverage, were excluded, leaving data on 1,061 firms.

HMO market shares in the county and MSA in which the firm is headquartered were merged using the zip code from the mailing address of the surveyed location. ${ }^{8}$ Firms in the sample represent

${ }^{8}$ Some firms operate at many locations, and thus the area characteristics associated with the county or MSA in which the surveyed site is located may not accurately represent market conditions for all of the locations. This issue is dealt with more specifically in the estimation sections below. 
all 50 states and the District of Columbia, and 543 counties. HMO market shares range from 0 to 49.5 percent in counties where firms in our sample are located. Fifty-four of the firms ( 5.9 percent) are in markets with HMO market shares of 30 percent or more; 28 of the firms (2.6 percent) are located in markets where HMO market share exceeds 40 percent.

Additional data describing population demographics (age, sex, and race distributions), as well as variables describing the number of hospital beds, generalist physicians, and specialist physicians per 1,000 population were obtained from the Area Resource File and were merged with the firm data.

\section{Estimation}

\section{Estimation issues and strategy}

The theoretical model of an imperfectly competitive health care market developed in section 2 provides guidance in specifying an appropriate empirical model. Two insights of the theoretical model are particularly relevant to the empirical analysis. First, penetration is determined endogenously as the result of decisions made by consumers, HMOs, and insurers, and simultaneity bias is therefore likely to be a problem. Second, the model indicates that preferences are an important determinant of both variation in penetration and the effect of penetration on premiums (see observation \#3). Given the difficulty in measuring cross-sectional heterogeneity in preferences, omitted variable bias is likely to be a concern.

To illustrate, assume the true model determining insurance premiums is

$$
p_{i}=\beta_{0}+\beta_{1} \phi+\beta_{2} X+\beta_{3} \gamma_{0}+\epsilon,
$$

where $\phi$ is (endogenous) market share, $\mathrm{X}$ is a vector of observable exogenous variables affecting the cost of serving a particular market and also capturing all observable determinants of preferences, $\gamma_{0}$ 
is an exogenous but unobservable variable that affects preferences, and $\epsilon$ is an i.i.d. error term uncorrelated with $X$ and $\gamma_{0}$. Suppose that, because $\gamma_{0}$ is unobservable, equation (7) is estimated without $\gamma_{0}$. Because of simultaneity and the omission of $\gamma_{0}$, the estimate of the coefficient of interest, $\beta_{1}$, is biased by

$$
\hat{\beta}_{1}-\beta_{1}=\beta_{3}\left(\phi^{\prime} M_{x} \phi\right)^{-1} \phi^{\prime} M_{x} \gamma_{0}+\left(\phi^{\prime} M_{x} \phi\right)^{-1} \phi^{\prime} M_{x} \epsilon
$$

where $M_{x}=I-X\left(X^{\prime} X\right)^{-1} X^{\prime}$. The first term on the RHS captures the omitted variable bias. Note that $\beta_{3}$ represents the direct competitive effect of preferences, and is therefore negative (observation \#3). Since $\beta_{3}<0$, the bias induced by the omission of $\gamma_{0}$ is negative if $\phi^{\prime} M_{x} \gamma_{0}>0$. Our assumption that increases in preferences $\gamma$ lead to increased penetration leads us to suspect that this condition holds. ${ }^{9}$ Since increases in $\gamma_{0}$ lead to lower prices, other things equal, and since increases in $\gamma_{0}$ lead to increases in $\phi^{*}$, the coefficient on $\phi$ is likely to be biased down when $\gamma_{0}$ is omitted.

The second term on the RHS of equation (8) captures simultaneity bias. This may come from two sources. First, recall that $p_{i}$ appears in the demand equation $\phi=F\left(B^{-1}\left(p_{i}-p_{h} ; \gamma\right)\right)$. Since $F^{\prime}>0$ and $\mathrm{B}^{-1}>0$, this results in a positive correlation between $\phi$ and $\epsilon$ and so $\phi^{\prime} \mathrm{M}_{\mathrm{x}} \epsilon>0$. Alternatively, simultaneity bias may arise through the HMO supply relation if $\epsilon$ captures other omitted variables that are observable to HMO management and affect HMO entry decisions. For example, HMOs may be more likely to locate in areas where particularly slack utilization review efforts by incumbent insurers make it easy for entering HMOs to offer competitive prices, attract patients, and achieve

${ }^{9}$ As discussed in section 2 and in Appendix B, endogenous entry by HMOs may limit the extent to which increases in $\gamma$ result in increases in $\phi^{*}$, or even cause $d \phi^{*} / \mathrm{d} \gamma$ to become negative. If increases in $\gamma$ do not induce too much exit in the HMO market through increased inter-market competition, increases in $\gamma$ lead to increases in $\phi^{*}$ on the margin. It can be shown that $d \phi^{*} / d \gamma>0$ necessarily implies $\phi^{\prime} M_{x} \gamma_{0}>0$ if $\gamma_{0}$ is uncorrelated with exogenous shifters of the HMO supply relation excluded from X. 
satisfactory financial performance. ${ }^{10}$ We expect a positive bias from simultaneity, regardless of whether it arises through $\epsilon$ 's presence in the demand relation or the HMO supply relation. This may partially offset the negative omitted-variables bias.

We rely on IV techniques to eliminate omitted-variable and simultaneity bias from the estimates. To implement this technique, we need instruments that capture exogenous forces that affect the extent of HMO entry or the intensity of competition among HMOs. ${ }^{11}$ We discuss below our particular instruments, which we take to be variables affecting the fixed cost of entry in a market, or, more generally, exogenous variables that do not reflect variation in preferences, but still alter the profitability of a market net of fixed entry costs.

In addition, several problems arise from the specific data we employ. First, to include measures of HMO market share for each firm, market areas must be defined. For practical reasons, we initially identify market areas as counties. Since counties may be too small to fully capture market areas, we verified our results using data at the MSA level and found the results to be consistent with those shown.

Second, selection bias may occur at the firm level since we have data on conventional insurance premiums only from firms that decided to offer a conventional insurance plan. Since firms that are able to obtain low premiums are more likely to offer insurance than firms that obtain high premiums, this is likely to cause the sample means to understate the average premium that would be observed if all firms offered insurance. It could also bias the results of the regression analysis. For

${ }^{10}$ Empirical evidence suggesting that HMOs are more likely to locate in areas with high conventional premiums has been found by Porell and Wallack (1990), Welch (1984), and Goldberg and Greenberg (1981).

${ }^{11}$ Note that instrumenting for $\phi$ using direct measures of HMO competition (e.g. Herfindahl indices) would not remove the omitted-variable bias since HMO competition is likely to be correlated with preferences. 
example, if competition from HMOs lowers conventional premiums, this type of selection bias may also cause OLS estimates to understate the true effect of HMOs, since the distribution of premiums in areas with lower levels of HMO market share will be more likely to be truncated than the distribution of premiums in areas with higher levels of HMO market share. We investigated the extent of this bias by examining models in which the distribution of premiums was assumed to be censored. We found that results from censored regression models (not presented) were similar to results obtained using models that did not incorporate censoring.

Finally, measurement error may be a difficulty. The measures of HMO activity used are estimates and undoubtedly contain at least some measurement error, which will bias the coefficients on HMO activity variables toward zero (Greene, 1993). We expect that IV estimates will also remove errors-in-variables bias. If the instruments are uncorrelated with the measurement error in the market share estimates, then instruments will purge the model of this bias as well (Hausman et al., 1991).

\section{OLS Results}

We begin by estimating a function of the form:

$$
\log \left(p_{i}\right)=\beta_{0}+\beta_{1} \phi_{i}+\beta_{2} \phi_{i}^{2}+\beta_{3} X_{i}+\epsilon_{i}
$$

using OLS. This allows us to discuss basic estimation results and provides a comparison for IV estimation later. In equation (9), subscript i denotes firm $i . \log \left(p_{i}\right)$ denotes the natural $\operatorname{logarithm}$ of the conventional premium charged to firm i. A log specification is used since visual inspection of the data and Box-Cox analysis indicated that this specification was superior to a linear 
specification. ${ }^{12} \phi_{\mathrm{i}}$ denotes HMO market share in the county or MSA in which firm $\mathrm{i}$ is located. ${ }^{13}$ We adopt a quadratic specification since the effect of HMOs on premiums may vary with the level of HMO activity. Other flexible functional forms, including cubic models and splines, ${ }^{14}$ were examined, but added little to the quadratic. X denotes a vector of control variables. $\epsilon$ is assumed to be a well-behaved error term.

The basic theoretical model developed above described the behavior of conventional insurance premiums in a setting where the characteristics of the employer purchasing the insurance, the characteristics of the plan offered, and the characteristics of the health care delivery system were assumed to be fixed. In practice, however, these characteristics vary from firm to firm and from market to market, and may affect premiums. Our specification includes a number of variables designed to control for variation from these sources (Table 2).

First, several variables capture premium variation due to variation in firm and plan characteristics. Four dummy variables represent firms with $6-10,11-25,25-50$, and over 50 employees. The omitted reference group is firms with less than 5 employees. Because administrative costs/loads are smaller for larger groups, premiums are expected to decline with firm size. Some specifications include variables to control for the wage distribution of workers in each firm, measured as the proportion of workers who earn less than $\$ 10,000$ per year and the proportion

\footnotetext{
${ }^{12}$ The maximum likelihood estimate of $\lambda$ is 0.079 ; the $\chi^{2}$ [1] statistic for $H_{0}: \lambda=0$ is 2.57 $(\mathrm{p}=0.109)$.
}

${ }^{13}$ We employ market share data from 1990 and premium data from 1991 since the effects of market share may take time to manifest themselves. This is not expected to affect the results since market shares are highly correlated over time. For example, the correlation between the 1990 and 1991 county-level market share measures is $\mathbf{0 . 9 6 8}$. market share.

${ }^{14}$ Specifically, we considered linear and quadratic splines with knots at 5,15 , and 25 percent 
of workers who earn more than $\$ 35,000$ per year. Ten industry dummies are used to capture persistent cost differences across industries (the omitted category is Public Administration). For a subset of firms, data on the age distribution of workers and the employee turnover rate were also available. These variables may capture variation in employee characteristics that are associated with health care costs, and may also control to some extent.

Premiums may also vary because of variation in the benefits provided. To control for policy characteristics, we include the actuarial value of the plan using a measure derived by Cutler (1994). The actuarial value of a plan is an estimate of what the benefit cost would be if everyone who currently has private health insurance were insured under that policy. Actuarial values of two plans differ only because the benefits under one plan are more generous than the benefits under the other. The actuarial values incorporate measures of the services covered (hospital care, physician care, vision care, durable equipment, prescription drugs, and mental health) and the deductible, copayment, and out-of-pocket maximum associated with the "major medical" portion of the plan. (See Cutler, 1994, for more details).

We also include characteristics of the population in the area where the firm is located. These variables are expected to control, to some degree, for variation in patient preferences for HMOs. Specifically, we include the proportions of the population that are female, over age 65 , and nonwhite. A dummy representing firms located in MSAs is included to capture other differences in costs associated with urban areas. To account for variation in the characteristics of the health care system, which may be associated with the cost of producing health care, we control for the number of hospital beds, generalist physicians, and specialist physicians per capita.

Results from estimation of equation (9) are presented in column 1 of Table 3. The coefficient on the linear market share term is positive and significant. The coefficient on the 
quadratic term is negative, but not itself significant. Jointly, the coefficients are marginally statistically significant $(F=3.44, p=0.083)$ and indicate that conventional premiums are a concave function of market share. Premiums are increasing in market share until market share reaches about 32 percent, and are thereafter declining. Since relatively few firms in our data are in markets with HMO market shares above 30 percent, caution must be exercised in interpreting the shape of the curve above this level. Note that, throughout the analysis, the market share coefficients have been scaled to represent the effect of a 10 percentage point change in market share (e.g. moving from 10 to 20 percent market share).

The estimated coefficients can be used to compute the predicted percent change in premiums that would be associated with changes in market share. Under the assumption that conventional premiums are lognormally distributed, the approximate percent change in premiums associated with moving from market share S1 to market share $S 2$ can be computed using:

$$
\begin{aligned}
\% \Delta \text { premiums } & =\exp \left(\log P_{S 2}-\log P_{S I}\right)-1 \\
& =\exp \left(\hat{\beta}_{1}(S 2-S 1)+\hat{\beta}_{2}\left(S 2^{2}-S 1^{2}\right)\right)-1
\end{aligned}
$$

where $\log P_{S I}$ and $\log P_{S 2}$ are the predicted values of $\log ($ premiums) at market share levels $\mathrm{S} 1$ and $\mathrm{S} 2$. As a way of comparing estimates from different models, we use this formula to compute the predicted change in premiums associated with moving from 10 to 20 percent market share and the change associated the moving from 20 to 30 percent market share for different models. Here, the estimates imply that moving from 10 to 20 percent market share would be associated with a premium increase of 2.7 percent and moving from 20 to 30 percent would be associated with a premium increase of 1.1 percent.

Other variables in this model also perform as expected. Firms with more than 50 employees have significantly lower premiums than firms with less than 5 employees $(\hat{\beta}=-0.092, t=2.136)$. 
Increases in the plan's actuarial value are associated with increases in premiums $(\hat{\beta}=0.017, t=3.260)$. Increases in the proportion of workers making over $\$ 35,000$ per year were associated with higher premiums $(\hat{\beta}=0.021, t=3.963)$. One explanation for this finding is that the wage variable captures unobserved variation in the quality of the plan offered. The industry dummies also picked up some variation: firms in manufacturing, transportation, and wholesale trade had significantly lower premiums than firms in public administration.

\section{Estimation}

To account for the possible endogeneity of market share, we use IV methods, implemented by estimating the following equations (Bowden and Turkington, 1990):

$$
\begin{gathered}
\phi_{\mathrm{i}}=\alpha_{0}+\alpha_{1} \mathrm{I}_{\mathrm{i}}+\alpha_{2} \mathrm{X}_{\mathrm{i}}+\eta_{\mathrm{i}} \\
\log \left(\mathrm{p}_{\mathrm{i}}\right)=\boldsymbol{\beta}_{0}+\beta_{1} \hat{\phi}_{i}+\beta_{2} \hat{\phi}_{i}^{2}+\beta_{3} X_{\mathrm{i}}+\epsilon_{\mathrm{i}}
\end{gathered}
$$

where I denotes instrumental variables used to identify variation in market share. Predicted values of market share are generated using the estimated coefficients from equation (11), and equation (12) is estimated using the predicted values and their square. ${ }^{15}$

Two instruments are used in estimating equation (11): the average firm size in the area in which the surveyed firm is located, measured as the average number of workers per firm at the county or MSA level, and the proportion of workers in each county or MSA who are considered white-collar. Large firms and white collar firms are more likely to offer their employees a choice of health insurance plans, including HMOs (see, e.g., U.S. Dpt of Labor (1990) and analysis below), and thus areas with large and white collar firms are expected to be favorable climates for HMOs.

\footnotetext{
${ }^{15} \mathrm{An}$ alternate procedure is to instrument directly for the linear and quadratic terms using 2-stage least-squares. Estimation using this technique produced estimates consistent with those reported.
} 
We are able to use our data to verify the expected relationships. To do this, we used data on all firms that offer health benefits of any kind to estimate a probit regression examining the probability of offering an HMO. The results are shown in Table 4. Consistent with the expected relationships, we found that firms with more than 50 employees were significantly more likely to offer HMOs than smaller firms, and that employers in construction and wholesale trade were less likely than public administration employers to offer HMOs, while employers in finance, insurance, and real estate were more likely to offer HMOs.

The instruments are expected to remove bias from omitted variables and simultaneity. In particular, we are concerned about omitted patient and provider preferences. To remove this bias, the instruments must be uncorrelated with unobserved preferences. One reason large firms are expected to be more likely to offer HMOs is that federal law requires firms with more than 25 employees that offer health insurance to offer an HMO if there is an HMO that wishes to be offered. Also, any fixed costs an HMO must bear in, say, preparing a bid for an employer are more likely to pay off at a larger firm, other things equal. White collar firms may offer expanded health benefits choices because of labor market conditions and because their employees value benefits choices. We recognize that one potential difficulty with the instruments is that, while they may capture exogenous variation in benefits offering, they may also be associated to some extent with preferences for HMOs. For example, the instruments may be correlated with population income and wealth levels, which may, in turn, be associated with preferences. If this is the case, the induced correlation would invalidate the results. To deal with this issue, the model controls directly for some population characteristics that may be associated with preferences. In addition, wage measures for the individual firms are included. We also experimented with the addition of further direct controls for population per capita income, population education levels, and population health status (e.g. 
percent of the population with a disability) and found the results to be consistent with those reported. Thus, we suspect that correlation between the instruments and population preferences is not a strong source of bias in the IV estimates. ${ }^{16}$

Market-level firm size and the proportion of workers who are white collar are also unlikely to have a strong direct relationship to premiums, suggesting that they can purge the model of simultaneity bias. One possible difficulty is that large firms may have significant power in the health care purchasing market and may have taken independent steps to help control costs. Reestimation of IV models using only the percentage of workers who are white collar yielded results that were consistent with those reported.

Estimates from the first-stage model (equation (11)) are shown in column 3 of Table 3. The instrumental variables perform well in the first stage--they have the expected signs and are statistically significant. Following the suggestion of Bound, Jaeger, and Baker (1993), we performed an F-test for the hypothesis that the coefficients on the instruments are jointly zero. The hypothesis was rejected $(F[2,1035]=127.56 ; p<.001)$.

IV estimates of the effect of HMO market share on conventional insurance premiums are presented in column 2 of Table 3 . The market share coefficients are jointly statistically significant $(F[2,1032]=3.14 ; p=.044)$, but, in contrast to the OLS results, the shape of the estimated function is convex. According to the IV estimates, premiums are downward sloping until market share reaches 13 percent and then begin to rise. The estimated relationship is plotted in Figure 1. Moving from 10

\footnotetext{
${ }^{16}$ As a further check on the validity of the results, we experimented with the use of population growth rates as instruments for market share. Areas that are growing rapidly are expected to attract HMO entry more quickly, and thus exhibit more intense competition among HMOs. Population growth rates are expected to be uncorrelated with unobserved preferences for HMOs and not directly related to premiums. Use of this instrument produced results very similar to those reported. We also experimented with using the presence of state laws favorable to HMOs as instruments, and found that these variables produced results very similar to those reported.
} 
to 20 percent market share would be associated with a 2.2 percent increase in premiums. Moving from 20 to 30 percent would be associated with a 13.0 percent increase in premiums. Coefficient estimates for the other explanatory variables are similar to the OLS estimates. As a check on the validity of the instruments, equations (11) and (12) were estimated using each instrument independently. The results were consistent with those reported.

To examine the robustness of the IV results, we estimated a number of additional model specifications. Results are presented in Table 5. Column I presents results from a specification that includes additional controls for the age distribution of firm employees and the employee turnover rate. Since not all firms provided this information on the survey, the sample for this regression is smaller than the sample used in the earlier regressions. In sign and magnitude, the coefficients are consistent with the results reported earlier, implying that premiums are convex functions of market share. However, the coefficients on HMO market share are jointly only marginally statistically significant $(F[2,679]=2.63 ; p=0.07)$. Increases in the proportion of employees over age 50 contributes to significant increases in premiums $(\hat{\beta}=0.046, t=5.145)$.

Very large firms are more likely to be self-insured than small firms. In addition, large firms may have leverage in health insurance purchasing markets that small firms do not have. To be sure that the inclusion of very large firms did not bias the results, we reestimated equations (11) and (12) using only data from firms with less than 1000 employees. Results are shown in column 2 . The coefficients are not statistically significant, but are consistent with the shape of the curve reported earlier.

Since some firms have employees at multiple locations, HMO market share in the headquarters location may not be an accurate representation of relevant market conditions. Firms were asked on the survey whether they had employees at "other company branches or locations in 
the United States." We reestimated equations (11) and (12) including only firms for which at least 60 percent of the employees worked at the location surveyed. Results are presented in column 3 . The estimated coefficients for market share are not statistically significant, but are consistent with the shape of the curve reported earlier.

Since counties may be too small to adequately represent the relevant health care market in some cases, we estimated equations (11) and (12) using HMO market share data measured at the MSA level instead. Firms not located in an MSA were excluded. Results are shown in column 4. The market share coefficients are jointly statistically significant and indicate that premiums are convex in market share. Premiums decrease with market share until market share reaches approximately 8 percent, and then rise. These coefficients imply that moving from 10 to 20 percent market share would result in premium increases of approximately 5.3 percent, while moving from 20 to 30 percent market shares would increase premiums by about 13.2 percent.

Finally, many firms are located in counties that have no HMO activity. To be sure that the results accurately reflected variation occurring in counties where there is HMO activity, we estimated equations (11) and (12) using only data from firms located in counties with some HMO activity. The estimated coefficients on HMO market share are jointly marginally significant and confirm the shape of the curve reported above (column 5).

\section{Other issues}

It is possible that coverages and other aspects of the conventional plans may vary as a result of competition from HMOs. If conventional insurers alter the policies they provide in response to competition from HMOs, then the actuarial value variable may absorb some of the effect of $\mathrm{HMO}$ market share. To examine the effect that this has on the results, we estimated equations (11) and 
(12) omitting actuarial value. The results (not shown) were statistically significant, and virtually identical to the results reported earlier $\left(\hat{\beta}_{1}=-0.121, t=1.001 ; \hat{\beta}_{2}=0.049, t=1.433 ; F[2,1033]=3.58\right.$, $\mathrm{p}=.0284)$.

A related possibility is that the variables describing the health care market (hospital beds and physicians per capita) are influenced by HMO market share and thus that their inclusion overcontrols for the effects of HMOs. We reestimated equations (11) and (12) omitting these variables. The results were consistent with those reported above, but the curve was more sharply sloped $\left(\hat{\beta}_{1}=-\right.$ $0.289, t=1.795 ; \hat{\beta}_{2}=0.109, t=2.180 ; F[2,1035]=4.58 ; p=.0104$ ). Here, moving from 10 to 20 percent market share would be associated with a 3.9 percent increase in premiums and moving from 20 to 30 percent would be associated with a 29.2 percent increase.

\section{Conclusion}

In this paper, we developed a model of the relationship between conventional insurers and HMOs and used the model to discuss the market segmentation and market discipline effects of HMOs on conventional insurers. Using data from a nationwide sample of firms, we then estimated the relationship between market share and premiums. IV estimates suggest the premiums are increasing in market share for market shares above about 10 percent, although in many cases the results are only marginally statistically significant. These results are consistent with the implications of the model when the market segmentation effect of HMOs (which, given existing evidence, would tend to drive premiums up) is stronger than the market discipline effect. Further, we find a convex relationship between conventional insurance premiums and penetration, suggesting that the market segmentation effect becomes relatively more important as penetration increases, possibly indicating that the markup-reducing discipline effect that HMOs may have on insurers is exhausted relatively 
quickly. Observation \#5 offers one possible explanation for this phenomenon. It is possible that plan quality deteriorates as penetration increases, making the plans better substitutes, eroding margins through intensified inter-market competition, and reducing insurers' incentives to protect their share with aggressive pricing. ${ }^{17}$

Moving from the OLS model to the IV model produced estimates that are more upward sloping at high levels of market share. We observed in our theoretical model that HMO penetration is likely to be higher when consumers value HMOs highly (Appendices A and B), and that such markets may exhibit increased inter-market competition and lower margins (observation \#3). As a result, the existence of omitted (unobservable) preference variables are likely to bias OLS estimates of the effect of penetration down, overestimating the importance of the market discipline effect. This finding that IV estimates of the effects of HMO penetration are more positive for market shares over about 13 percent is consistent with the hypothesis that the effects of unobserved preferences and measurement error (which also induces negative bias) are more important than the simultaneity bias associated with the endogeneity of HMO entry and penetration.

A strong view of the benefits of increased HMO activity might be that HMOs both lower costs and premiums for their enrollees and reduce premiums for non-enrollees through competitive effects on insurers. If this were the case, increased HMO activity would unambiguously increase consumer welfare. However, our results suggest that HMOs do not reduce conventional insurance premiums. To evaluate the net effect of HMOs, whatever gains enrollees may reap from increased HMO activity must be weighed against the losses of non-enrollees. Since we do not investigate

${ }^{17}$ Other second-order effects discussed in footnote $\# 5$ could also play a role. For example, if $\mathrm{B}^{\prime \prime}<0$, consumers become more price sensitive as penetration increases, and the market discipline effect becomes less important. In that case, the plans become better substitutes because of changes in the marginal consumer's preferences, rather than because of changes in plan quality. 
HMO premiums, we are unable to evaluate this tradeoff. Assessing the net effect of HMOs on health care premiums and consumer welfare is important and remains a promising area for future research. 


\section{References}

Baker, Laurence C. (1995a). "County-level measures of HMO enrollment and market share," manuscript, Stanford University, (February).

Baker, Laurence C. (1995b). "HMOs and fee-for-service health care expenditures: Evidence from Medicare," manuscript, Stanford University, (September).

Bound, John, David A. Jaeger and Regina Baker (1993). "The cure can be worse than the disease: A cautionary tale regarding instrumental variables." NBER Technical Paper \#137 (June).

Bowden, Roger J. and Darrel A. Turkington (1990). Instrumental Variables. New York, NY, Cambridge University Press.

Brown, Randall S. (1988). Biased Selection in the Medicare competition demonstrations, Mathematica Policy Research.

Brown, Randall S., Jeanette W. Bergeron, Dolores Gurnick Clement, Jerrold W. Hill and Sheldon M. Retchin (1993). The Medicare Risk Program for HMOs--Final Summary Report on Findings from the Evaluation, Mathematica Policy Research.

Brown, Randall S., Kathryn Langwell, K Berman, A. Ciemnecki, Lyle Nelson, A. Schreir and A. Tucker (1986). Enrollment and Disenrollment in Medicare Competition Demonstration Plans: A Descriptive Analysis, Mathematica Policy Research.

Clement, Dolores Gurnick, Phillip M. Gleason and Randall S. Brown (1992). The Effects of Risk Contract HMO Market Penetration on Medicare Fee-For-Service Costs: Final Report, Mathematica Policy Research.

Corts, Kenneth S. (1993). "Conduct parameters and the measurement of market power," manuscript, Harvard Business School.

Cutler, David M. (1994). "Market failure in small group health insurance." NBER Working Paper \#4879, (October).

Dowd, Bryan E. (1987). "HMOs and Twin Cities admission rates." Health Services Research $21: 2$ (June) 177-188.

Eggers, Paul W. and Ronald Prihoda (1982). "Pre-enrollment reimbursement patterns of Medicare beneficiaries enrolled in 'at risk' HMOs." Health Care Financing Review 4:1 (September) $55-73$.

Encinosa, William E. and David E.M. Sappington (1995). "Notes on modeling competition among health maintenance organizations," manuscript, University of Michigan, (August). 
Feldman, Roger, Hung-Ching Chan, John Kralewski, Bryan Dowd and Janet Shapiro (1990). "Effects of HMOs on the creation of competitive markets for hospital services." Journal of Health Economics 9 207-222.

Feldman, Roger and Bryan Dowd (1982). "Simulation of a health insurance market with adverse selection." Operations Research 30:6 (November-December) 1027-1042.

Feldman, Roger and Bryan Dowd (1986). "Is there a competitive market for hospital services?" Journal of Health Economics 5 277-292.

Feldman, Roger and Bryan Dowd (1991). "Must adverse selection cause premium spirals?" Journal of Health Economics 10:3 (October) 350-357.

Feldman, Roger, Bryan Dowd, Don McCann and Allan Johnson (1986). "The competitive impact of health maintenance organizations on hospital finances: An exploratory study." Journal of Health Politics. Policy, and Law 10:4 (Winter) 675-698.

Feldstein, Paul J. and Thomas M. Wickizer (1993). "Analysis of private health insurance premium growth rates: 1985-1991," manuscript, University of California at Irvine, (August).

Frank, Richard G. and W. Pete Welch (1985). "The competitive effects of HMOs: A review of the evidence." Inquiry 22 (Summer) 148-161.

GHAA (1991). 1991 National Directory of HMOs. Washington, D.C., The Group Health Association of America.

GHAA (1994). 1994 National Directory of HMOS. Washington, D.C., The Group Health Association of America.

Goldberg, Lawrence G. and Warren Greenberg (1979). "The competitive response of blue cross and blue shield to the growth of health maintenance organizations in northern California and Hawaii." Medical Care 17:10 (October) 1019-1028.

Goldberg, Lawrence G. and Warren Greenberg (1981). "The determinants of HMO enrollment and growth." Health Services Research 16:16 421-438.

Greene, William H. (1993). Econometric Analysis. New York, NY, MacMillan.

Hausman, Jerry A., Whitney K. Newey, Hidehiko Ichimura and James L. Powell (1991). "Identification and estimation of polynomial errors-in-variables models." Journal of Econometrics 50 273-295.

Hellinger, Fred J. (1987). "Selection bias in health maintenance organizations: Analysis of recent evidence." Health Care Financing Review 9:2 (Winter) 55-63. 
Hill, Jerrold W. and Randall S. Brown (1990). Biased Selection in the TEFRA HMO/CMP Program, Mathematica Policy Research.

Hill, Jerrold W. and Randall S. Brown (1992). Health Status. Financial Barriers, and the Decision to Enroll in Medicare Risk Plans, Report, Mathematica Policy Research.

Hill, Jerrold W., Randall S. Brown, Dexter Chu and Jeanette Bergeron (1992). The Impact of the Medicare Risk Program on the Use of Services and Cost to Medicare, Report, Mathematica Policy Research.

U.S. Department of Labor (1990). Employee Benefits in Medium and Large Firms (Bulletin No. 2363), Bureau of Labor Statistics.

Lewis, Tracy and David Sappington (1995). "Insurance, adverse selection, and cream-skimming." Journal of Economic Theory 65:2 (April) 327-358.

Lichtenstein, Richard, Bruce Watkins, James Lepkowski and Bridget Simone (1992). "HMO marketing and selection bias: Are TEFRA HMOs skimming?" Medical Care 30:4 (April) 329-346.

Luft, Harold S., S.C. Maerki and J.B. Trauner (1986). "The competitive effects of health maintenance organizations: Another look at the evidence from Hawaii, Rochester, and Minneapolis/St. Paul." Journal of Health Politics. Policy. and Law 10 (Winter) 625-658.

Marquis, M. Susan (1992). "Adverse selection with a multiple choice among health insurance plans: a simulation analysis." Journal of Health Economics 11 129-151.

McLaughlin, Catherine G. (1988). "The effect of HMOs on overall hospital expenses: Is anything left after correcting for simultaneity and selectivity?" HSR: Health Services Research 23:3 (August) 421-441.

Newhouse, Joseph (1984). "Cream skimming, asymmetric information, and a competitive insurance market." Journal of Health Economics 3 97-100.

Noether, Monica (1988). "Competition among hospitals." Joumal of Health Economics 7 259-284.

Pauly, Mark V. (1984). "Is cream-skimming a problem for the competitive medical market." Journal of Health Economics 3:1 (April) 87-94.

Phelps, Charles E. (1992). "Diffusion of information in medical care." Journal of Economic Perspectives 6:3 (Summer) 23-42.

Porell, Frank W. and Stanley S. Wallack (1990). "Medicare risk contracting: Determinants of market entry." Health Care Financing Review 12:2 (Winter) 75-85. 
Riley, Gerald, James Lubitz and Evelyne Rabey (1991). "Erırollee health status under Medicare risk contracts: An analysis of mortality rates." HSR: Health Services Research 26:2.

Robinson, James C. (1991). "HMO market penetration and hospital cost inflation in California." Journal of the American Medical Association 266:19 (November 20) 2719-2723.

Sullivan, Cynthia B., Marianne Miller, Roger Feldman and Bryan Dowd (1992). "Employer-sponsored health insurance in 1991." Health Affairs 11:4 (Winter) 172-185.

Van de Ven, Wynand and Rene Van Vliet (1995). "Consumer information surplus and adverse selection in competitive health insurance markets: an empirical study." Journal of Health Economics 14 149-169.

Welch, W. Pete (1984). "HMO enrollment: A study of market forces and regulations." Journal of health politics. policy, and law 8:4 743-758.

Welch, W. Pete (1994). "HMO market share and its effect on local Medicare costs." HMOs and the Elderly. Ann Arbor, MI, Health Administration Press.

Wilensky, Gail R. and Louis F. Rossiter (1986). "Patient self-selection in HMOs." Health Affairs 5:1 66-80. 
Figure 1: IV Estimated Relationship between HMO Market Share and Conventional Insurance Premiums

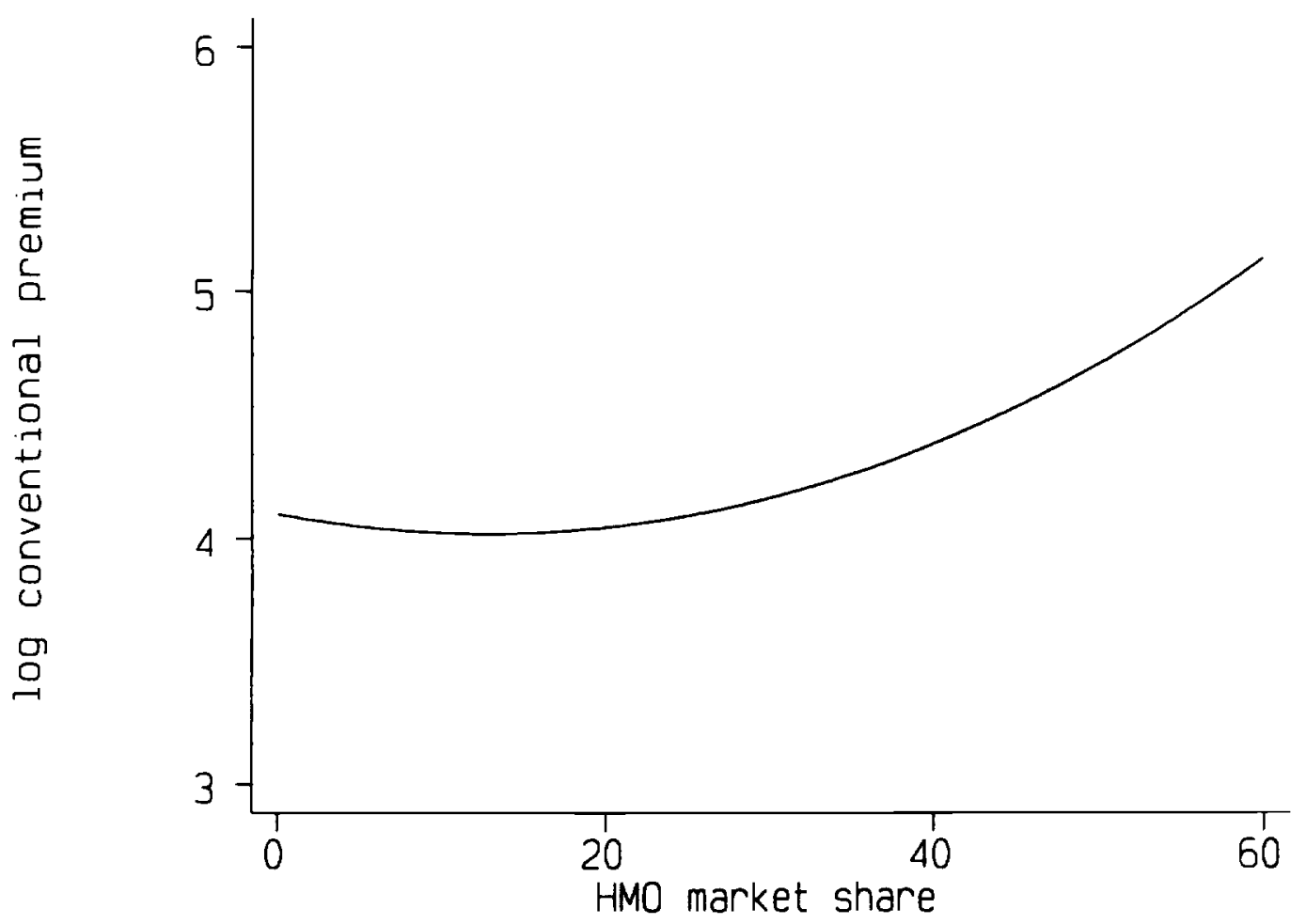


Table 1: Characteristics of Firms by Health Insurance status

\begin{tabular}{|c|c|c|c|}
\hline & $\begin{array}{c}\text { Base } \\
\text { Sample }\end{array}$ & $\begin{array}{l}\text { Offer Health } \\
\text { Insurance }\end{array}$ & $\begin{array}{c}\text { Offer } \\
\text { Conventional } \\
\text { Insurance }\end{array}$ \\
\hline Sample Size & 3323 & 2533 & 1854 \\
\hline \# of Employees per firm & 2310.972 & 2858.336 & 2964.276 \\
\hline \multicolumn{4}{|l|}{ Firm Size Distribution: } \\
\hline 1-5 Employees & 0.154 & 0.046 & 0.051 \\
\hline 6-10 Employees & 0.105 & 0.064 & 0.065 \\
\hline 11-25 Employees & 0.060 & 0.054 & 0.052 \\
\hline 26-50 Employees & 0.072 & 0.075 & 0.066 \\
\hline Over 50 Employees & 0.609 & 0.762 & 0.766 \\
\hline \multicolumn{4}{|l|}{ Industry: } \\
\hline Agriculture & 0.017 & 0.009 & 0.010 \\
\hline Mining & 0.011 & 0.012 & 0.013 \\
\hline Construction & 0.049 & 0.034 & 0.030 \\
\hline Manufacturing & 0.160 & 0.178 & 0.189 \\
\hline Transportation & 0.048 & 0.052 & 0.056 \\
\hline Wholesale Trade & 0.056 & 0.060 & 0.062 \\
\hline Retail Trade & 0.155 & 0.120 & 0.119 \\
\hline Fin., Ins., Real Estate & 0.069 & 0.071 & 0.074 \\
\hline Services & 0.333 & 0.343 & 0.330 \\
\hline Public Administration & 0.101 & 0.121 & 0.117 \\
\hline \& Employees $<\$ 10,000$ & 17.601 & 13.559 & 13.206 \\
\hline \& Employees > $\$ 35,000$ & 21.769 & 24.275 & 24.344 \\
\hline HMO Market Share & 11.361 & 11.984 & 10.778 \\
\hline
\end{tabular}

Note: Distributions may not sum to 1 because of rounding. 
Table 2: Summary of Analysis Variables

\begin{tabular}{|c|c|c|}
\hline & Mean & $\begin{array}{c}\text { Standard } \\
\text { Error }\end{array}$ \\
\hline Single premium & 144.386 & 53.426 \\
\hline $\log$ (Single Premium) & 4.915 & 0.335 \\
\hline HMO Market Share & 11.028 & 10.827 \\
\hline Firm Size: & & \\
\hline 1-5 employees & 0.061 & 0.240 \\
\hline 6-10 employees & 0.074 & 0.263 \\
\hline 11-25 employees & 0.066 & 0.248 \\
\hline 26-50 employees & 0.078 & 0.269 \\
\hline Over 50 employees & 0.720 & 0.449 \\
\hline Actuarial Value & 1240.614 & 201.728 \\
\hline Industry: & & \\
\hline Agriculture & 0.009 & 0.097 \\
\hline Mining & 0.011 & 0.106 \\
\hline Construction & 0.032 & 0.176 \\
\hline Manufacturing & 0.179 & 0.384 \\
\hline Transportation & 0.052 & 0.222 \\
\hline Wholesale trade & 0.062 & 0.242 \\
\hline Retail Trade & 0.134 & 0.341 \\
\hline Finance, Insurance, Real Estate & 0.080 & 0.272 \\
\hline Service & 0.326 & 0.469 \\
\hline Public Administration & 0.114 & 0.318 \\
\hline \& Employees < $\$ 10,000$ & 14.122 & 18.611 \\
\hline Employees > $\$ 35,000$ & 22.756 & 20.085 \\
\hline MSA & 0.700 & 0.458 \\
\hline Population Female & 0.513 & 0.013 \\
\hline \& Population over 65 & 0.124 & 0.033 \\
\hline Population Non-White & 0.158 & 0.159 \\
\hline Hospital Beds per 1000 Pop. & 5.816 & 3.508 \\
\hline Generalists per 1000 Pop. & 0.795 & 0.481 \\
\hline Specialists per 1000 Pop. & 1.582 & 1.445 \\
\hline
\end{tabular}

Note: $\mathrm{N}=1061$ firms. 
Table 3: Results from OLS and IV Conventional Premium Models

\begin{tabular}{|c|c|c|c|}
\hline & $\begin{array}{l}\text { (1) } \\
\text { OLS }\end{array}$ & $\begin{array}{l}(2) \\
\text { IV }\end{array}$ & $\begin{array}{c}\text { (3) } \\
\text { First-Stage }\end{array}$ \\
\hline HMO Market Share /10 & $\begin{array}{c}0.051 \\
(0.028)\end{array}$ & $\begin{array}{l}-0.128 \\
(0.118)\end{array}$ & -- \\
\hline$(\text { HMO Market Share } / 10)^{2}$ & $\begin{array}{l}-0.008 \\
(0.007)\end{array}$ & $\begin{array}{c}0.050 \\
(0.033)\end{array}$ & -- \\
\hline 6-10 Employees & $\begin{array}{l}0.010 \\
(0.055)\end{array}$ & $\begin{array}{c}0.012 \\
(0.057)\end{array}$ & $\begin{array}{l}-0.139 \\
(0.140)\end{array}$ \\
\hline 11-25 Employees & $\begin{array}{c}0.022 \\
(0.056)\end{array}$ & $\begin{array}{c}0.033 \\
(0.059)\end{array}$ & $\begin{array}{l}-0.155 \\
(0.144)\end{array}$ \\
\hline 26-50 Employees & $\begin{array}{l}-0.074 \\
(0.055)\end{array}$ & $\begin{array}{l}-0.084 \\
(0.057)\end{array}$ & $\begin{array}{l}-0.176 \\
(0.140)\end{array}$ \\
\hline Over 50 Employees & $\begin{array}{l}-0.092 \\
(0.043)\end{array}$ & $\begin{array}{l}-0.094 \\
(0.045)\end{array}$ & $\begin{array}{l}-0.162 \\
(0.110)\end{array}$ \\
\hline Actuarial Value/100 & $\begin{array}{c}0.017 \\
(0.005)\end{array}$ & $\begin{array}{l}0.020 \\
(0.006)\end{array}$ & $\begin{array}{l}0.068 \\
(0.013)\end{array}$ \\
\hline Agriculture & $\begin{array}{l}-0.087 \\
(0.108)\end{array}$ & $\begin{array}{l}-0.059 \\
(0.113)\end{array}$ & $\begin{array}{c}0.133 \\
(0.276)\end{array}$ \\
\hline Mining & $\begin{array}{c}0.017 \\
(0.100)\end{array}$ & $\begin{array}{c}0.002 \\
(0.104)\end{array}$ & $\begin{array}{l}-0.076 \\
(0.255)\end{array}$ \\
\hline Construction & $\begin{array}{l}-0.044 \\
(0.064)\end{array}$ & $\begin{array}{l}-0.002 \\
(0.072)\end{array}$ & $\begin{array}{c}0.055 \\
(0.164)\end{array}$ \\
\hline Manufacturing & $\begin{array}{l}-0.102 \\
(0.039)\end{array}$ & $\begin{array}{l}-0.094 \\
(0.040)\end{array}$ & $\begin{array}{c}0.072 \\
(0.099)\end{array}$ \\
\hline Transportation & $\begin{array}{l}-0.127 \\
(0.054)\end{array}$ & $\begin{array}{l}-0.148 \\
(0.057)\end{array}$ & $\begin{array}{c}0.040 \\
(0.138)\end{array}$ \\
\hline Wholesale Trade & $\begin{array}{l}-0.148 \\
(0.051)\end{array}$ & $\begin{array}{l}-0.131 \\
(0.053)\end{array}$ & $\begin{array}{l}-0.136 \\
(0.131)\end{array}$ \\
\hline Retail Trade & $\begin{array}{l}-0.041 \\
(0.043)\end{array}$ & $\begin{array}{l}-0.015 \\
(0.046)\end{array}$ & $\begin{array}{l}-0.138 \\
(0.109)\end{array}$ \\
\hline
\end{tabular}




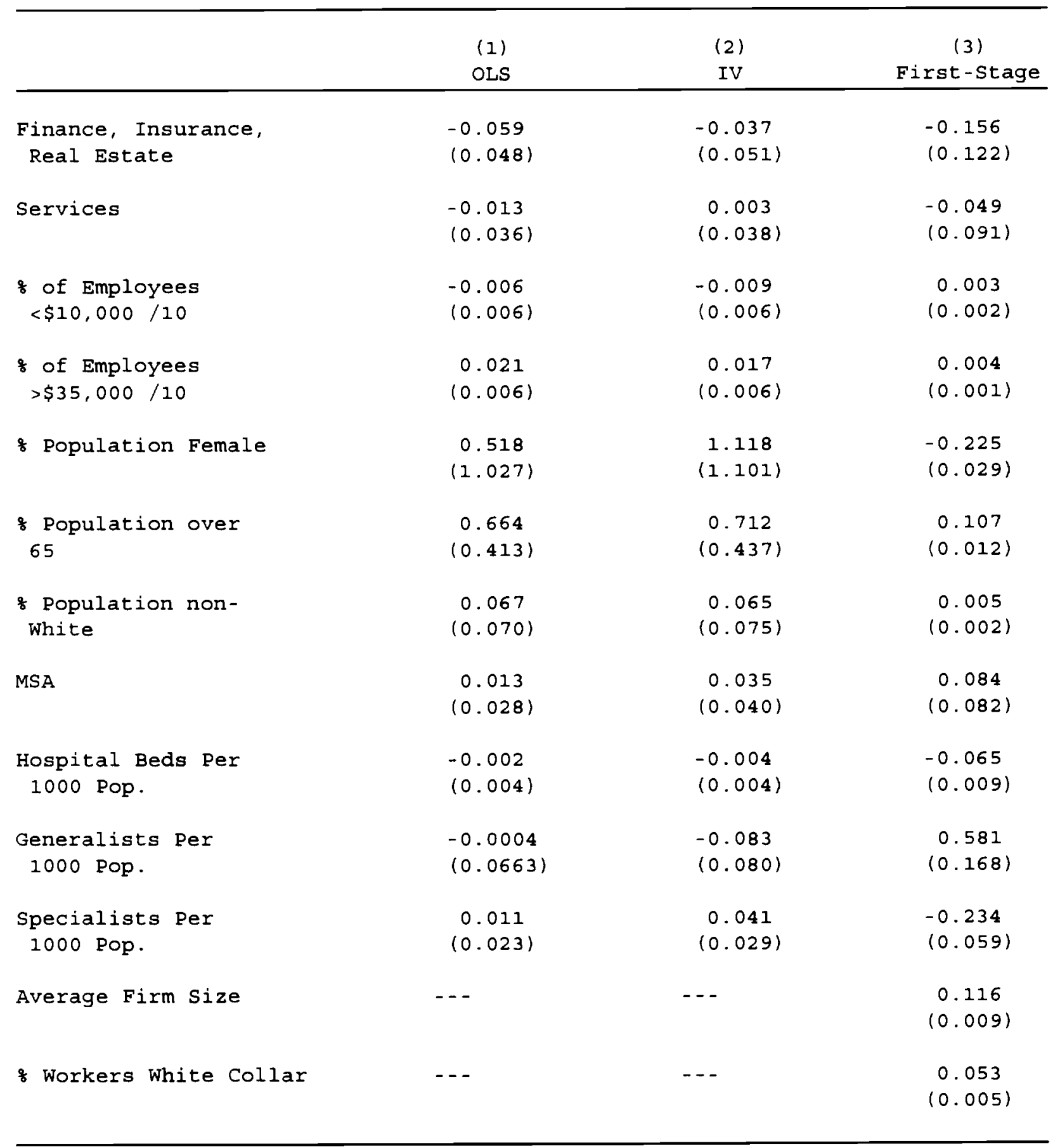

continued 
Table 3: Results from oLs and IV Conventional Premium Models Continued

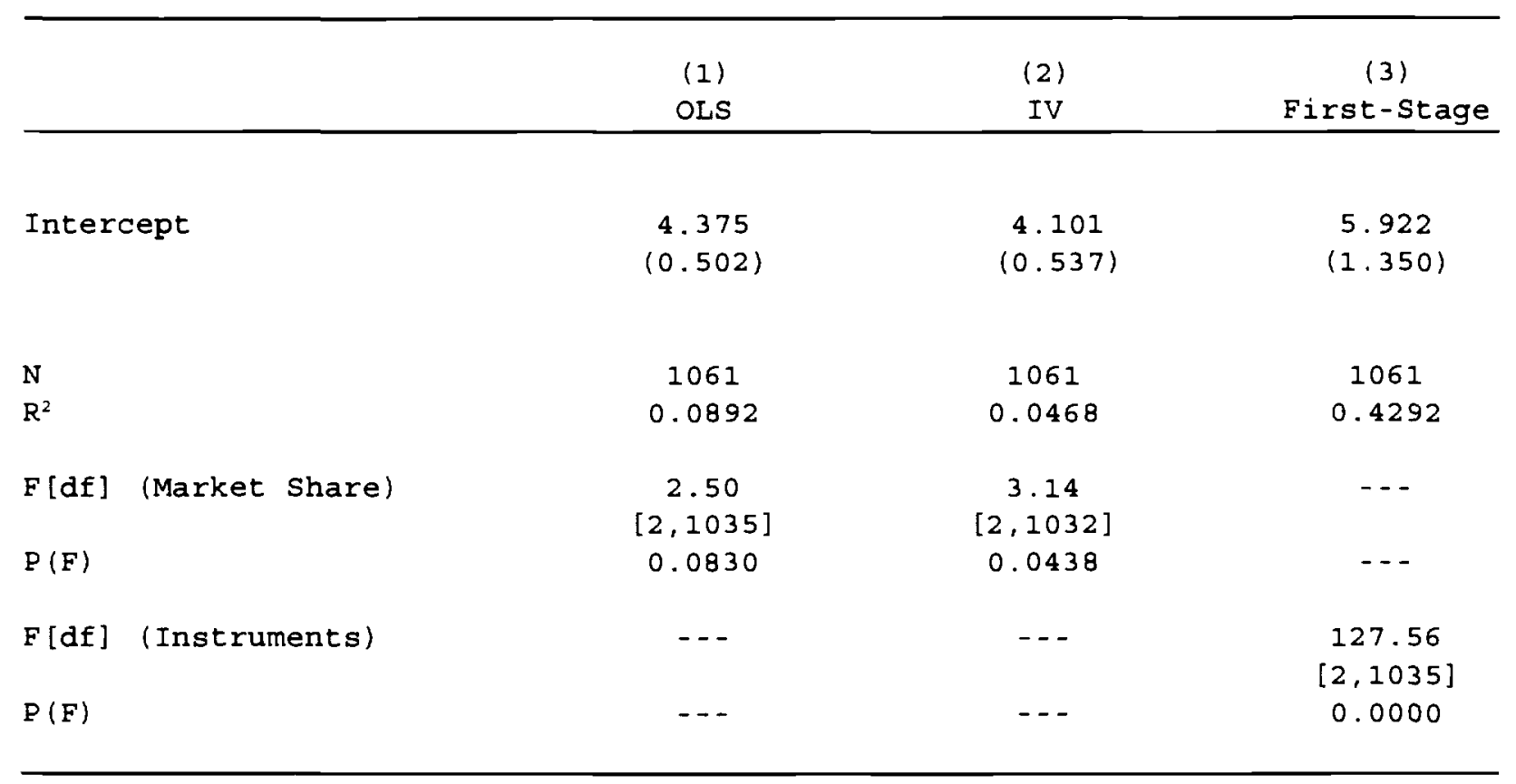

Note: Standard errors in parentheses. The omitted firm size category is 1-5 employees; the omitted industry category is public administration. The Fstatistics shown test the hypothesis that the linear and quadratic market share terms are jointly equal to 0 . 


\begin{tabular}{|c|c|c|}
\hline & Coefficients & Probability \\
\hline & (standard Error) & Derivative \\
\hline \multirow[t]{2}{*}{6 - 10 employees } & 0.386 & 0.134 \\
\hline & $(0.195)$ & \\
\hline \multirow[t]{2}{*}{$11-25$ employees } & 0.327 & 0.113 \\
\hline & $(0.203)$ & \\
\hline \multirow[t]{2}{*}{26 - 50 employees } & 0.192 & 0.066 \\
\hline & $(0.195)$ & \\
\hline \multirow[t]{2}{*}{ Over 50 employees } & 0.882 & 0.306 \\
\hline & $(0.162)$ & \\
\hline \multirow[t]{2}{*}{ Agriculture } & -0.406 & -0.140 \\
\hline & $(0.325)$ & \\
\hline \multirow[t]{2}{*}{ Mining } & 0.073 & 0.025 \\
\hline & $(0.244)$ & \\
\hline \multirow[t]{2}{*}{ Construction } & -0.533 & -0.185 \\
\hline & $(0.183)$ & \\
\hline \multirow[t]{2}{*}{ Manufacturing } & 0.006 & 0.002 \\
\hline & $(0.096)$ & \\
\hline \multirow[t]{2}{*}{ Transportation } & -0.054 & -0.019 \\
\hline & $(0.138)$ & \\
\hline \multirow[t]{2}{*}{ Wholesale Trade } & -0.266 & -0.092 \\
\hline & $(0.138)$ & \\
\hline \multirow[t]{2}{*}{ Retail Trade } & -0.244 & -0.084 \\
\hline & $(0.110)$ & \\
\hline \multirow[t]{2}{*}{ Finance, Insurance, Real Estate } & 0.201 & 0.070 \\
\hline & $(0.121)$ & \\
\hline \multirow[t]{2}{*}{ Service } & -0.022 & -0.008 \\
\hline & $(0.086)$ & \\
\hline
\end{tabular}

continued 
Table 4: Probit Results From Models of HaO Offering continued

\begin{tabular}{|c|c|c|}
\hline & $\begin{array}{c}\text { Coefficients } \\
\text { (Standard Error) }\end{array}$ & $\begin{array}{l}\text { Probability } \\
\text { Derivative }\end{array}$ \\
\hline Intercept & $\begin{array}{l}-1.161 \\
(0.177)\end{array}$ & -0.402 \\
\hline $\mathrm{N}$ & 2533 & \\
\hline$x^{2}[13]$ & 139.89 & \\
\hline Pseudo $R^{2}$ & 0.044 & \\
\hline
\end{tabular}

Note: standard errors in parentheses. Probability derivatives measure $\partial \operatorname{Pr}$ (offer $\mathrm{HMO}$ ) $/ \partial \mathrm{X}_{\mathrm{i}}$ where $\mathrm{X}$ represents the variable indicated. They are computed as $\phi(\beta X) \beta$ where $\phi$ represents the normal p.d.f. 
Table 5: Alternate Specifications of Conventional Premium Models Dependent Variable: log (conventional single premium)

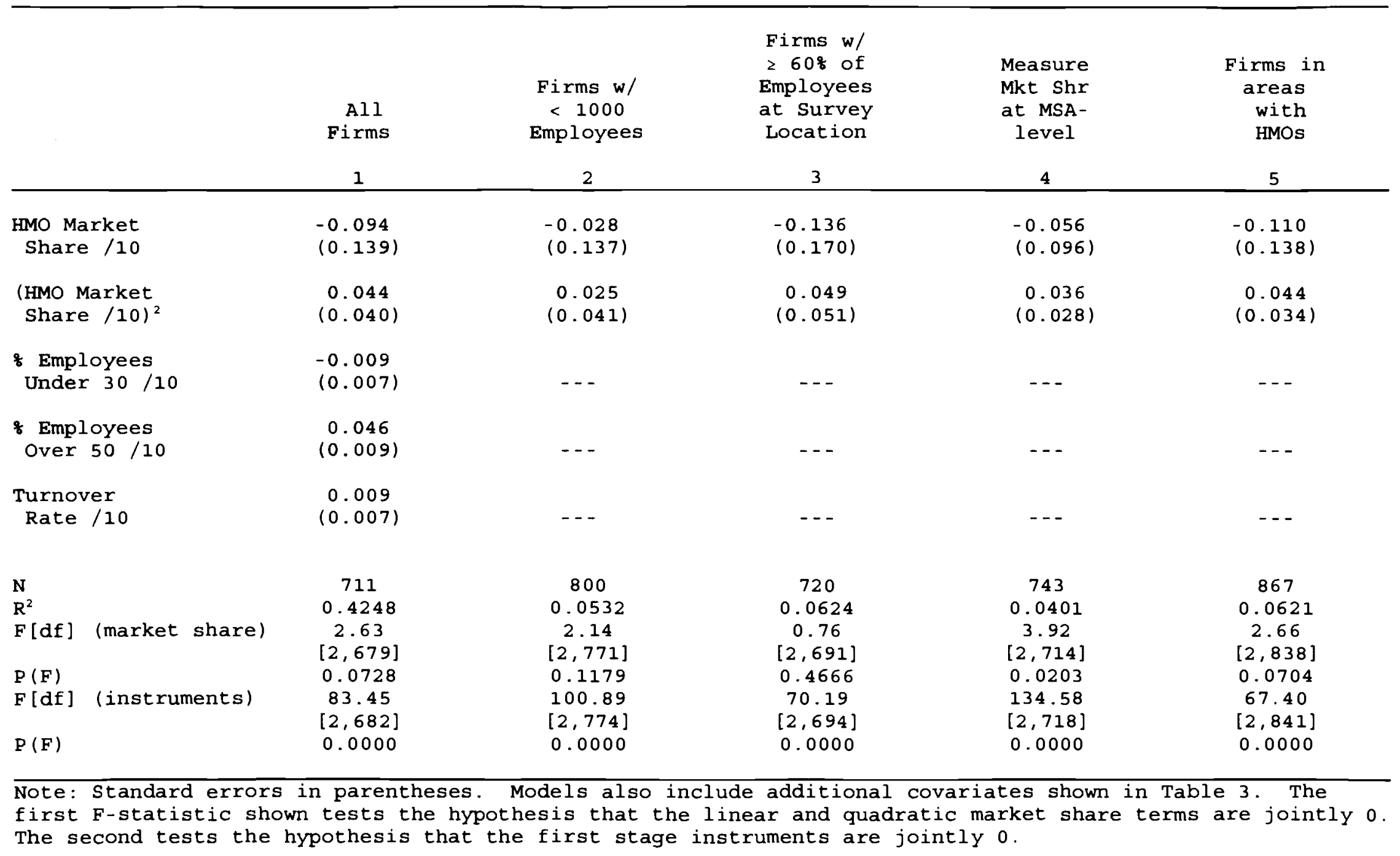




\section{Appendix A: A Numerical Example}

In this appendix, we consider a simple parameterization of the more general model and prove the validity of the assumption (maintained throughout the body of the paper) that $d \phi^{*} / d y$ is positive. Specifically, we assume only two health states, health and illness, with consumers indifferent between the plans in the absence of illness. In the case of illness, we assume that the (measured) benefits $\mathrm{K}$ are the same for the two plans, that there are no copayments, and that the utility benefit derived from treatment is $\mathrm{K}$ if the patient is enrolled in a conventional insurance plan and $\gamma \mathrm{K}$ if enrolled in an HMO, where $\gamma \in(0,1)$. Consumers vary in privately known but publicly unobservable health status $\theta$, which indicates the probability of illness and is distributed as $U[0,1]$. In the notation of the more general model, $\mathrm{B}(\theta ; \gamma)=(1-\gamma) \theta \mathrm{K}$. Consumer type $\theta_{0}$ is indifferent between the two plans: $\boldsymbol{\theta}_{0}=\left(\mathrm{p}_{\mathrm{i}}-\mathrm{p}_{\mathrm{h}}\right) /[(1-\gamma) \mathrm{K}]$. Under the assumption of uniformly distributed $\boldsymbol{\theta}, \boldsymbol{\phi}=\mathrm{F}\left(\boldsymbol{\theta}_{0}\right)=\boldsymbol{\theta}_{0}$. This highly stylized model captures in a simple way our fundamental assumptions about plan choice: the differential expected net benefit $\mathrm{B}(\boldsymbol{\theta} ; \gamma)$ is increasing in $\theta$, and $\partial \mathrm{B}^{\prime} / \partial \gamma$ is negative.

We further assume that an insurer's (expected) marginal cost of serving a consumer of type $\theta$ is $\lambda \theta \mathrm{K}$. HMOs are assumed to have similar costs, except that HMOs are permitted a proportional cost advantage measured by $\delta \in(0,1)$, so that an HMO's marginal cost of serving consumer type $\theta$ is $\delta \lambda \theta \mathrm{K}$. Two features of this parameterization are important: costs increase in the consumer's probability of illness, and HMOs are more efficient providers of any given benefit.

Finally, we assume that competition in the HMO and insurance markets can be modeled as symmetric Cournot games with exogenous numbers of firms $N_{i}$ and $N_{h}$. Given the cost and demand functions derived above, it is straightforward to derive the two Cournot industry supply relations:

$$
\begin{aligned}
& \mathrm{p}_{\mathrm{i}}^{*}=\lambda \mathrm{K} \phi^{*}+(1-\gamma) \mathrm{K}\left(1-\phi^{*}\right) / \mathrm{N}_{\mathrm{i}} \\
& \mathrm{p}_{\mathrm{h}}^{*}=\delta \lambda \mathrm{K} \phi^{*}+(1-\gamma) \mathrm{K} \phi^{*} / \mathrm{N}_{\mathrm{h}} .
\end{aligned}
$$


These supply relations can be solved simultaneously to yield closed-form expressions for equilibrium prices, which can then be combined with the demand function to obtain the following expression for equilibrium HMO penetration $\phi^{*}$ :

$$
\phi^{*}=(1-\gamma) N_{h} /\left[(1-\gamma)\left(N_{i}+1\right)\left(N_{h}+1\right)-(1-\delta) \lambda N_{i} N_{h}-(1-\gamma)\right]
$$

Straightforward differentiation of this expression demonstrates that $d \phi^{*} / d N_{h}>0$ and that $d \phi^{*} / d \gamma>0$ for all permitted parameter values, i.e., that equilibrium penetration is increasing in the competitiveness of the HMO market and in the preference parameter $\gamma$. One can also show that in the absence of the cost advantage for HMOs, penetration is invariant to preferences. When $\gamma$ increases, the plans become better substitutes, increasing demand elasticity, intensifying inter-market competition, and reducing equilibrium price-cost margins. More efficient firms are relatively more aggressive when competition intensifies and margins shrink; therefore, penetration increases in $\gamma$ when $\delta<1$.

We can also use this simple parameterization to demonstrate one important implication of our empirical results that suggest the insurance premiums increase in $\mathrm{HMO}$ penetration. In this parameterized model, the market discipline effect dominates for insurers (and $d p_{i}{ }^{*} / d \phi^{*}<0$ ) if and only if $N_{i}<(1-\gamma) / \lambda$. If the insurance market is concentrated enough $\left(N_{i}\right.$ small), margins are high and the insurers aggressively defend their market share. In this case, margins fall fast enough to offset the increase in costs associated with rising HMO penetration. This implies that intensifying competition in HMOs, which increases HMO penetration, leads to falling insurance premiums, i.e., $\mathrm{dp}_{\mathrm{i}}{ }^{*} / \mathrm{dN}_{\mathrm{h}}<0$. An increase in $\mathrm{N}_{\mathrm{h}}$ tends to lower margins in the HMO market directly, but also increases HMO penetration, which in turn increases HMOs' marginal costs. Total differentiation of the HMO supply relation indicates that the direct competitive effect outweighs the market segmentation effect for HMO premiums $\left(d p_{h}{ }^{*} / d N_{h}<0\right)$ if and only if $-(1-\gamma-\lambda) N_{i}<1-\gamma$. This holds if $1-$ 
$\gamma-\lambda>0$, which holds when $\lambda$ is small, i.e., when marginal costs are a small fraction of the benefit provided and segmentation is therefore unimportant. When $\lambda$ is large enough that $1-\gamma-\lambda<0$, the competitive effect still prevails in the HMO market if $N_{i}<(1-\gamma) /(\lambda-(1-\gamma))$. Since $1-\gamma>0$, the RHS of this inequality strictly exceeds $(1-\gamma) / \lambda$. These observations yield the following diagram for models in which $\lambda>1-\gamma$ :

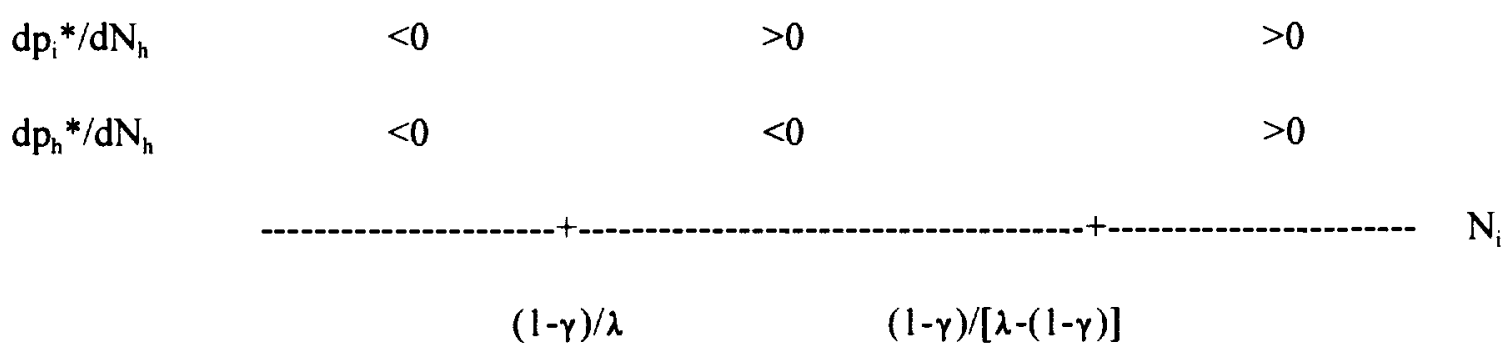

When there is sufficient slack in the pricing of the insurers $\left(\mathrm{N}_{\mathrm{i}}\right.$ small), increases in competition in the HMO market serve to discipline insurers, i.e., the market discipline effect prevails for insurers. At the same time, in the HMO market the direct competitive effect combines with strategic complementarity to lower HMO prices. Hence, for $\mathrm{N}_{i}<(1-\gamma) / \lambda$, prices fall in both markets as the HMO market becomes increasingly competitive. At the other extreme, if the insurance market is highly competitive $\left(\mathrm{N}_{\mathrm{i}}\right.$ large), the market segmentation effect prevails in the insurance market, and increases in HMO competition raise insurance premiums. For sufficiently large $\mathrm{N}_{i}$, this leads to higher HMO premiums despite a more competitive HMO market (in the sense that concentration is lower), as the market segmentation effect combines with strategic complementarity to outweigh the direct competitive effect. In this case, the market segmentation effect raises the price umbrella provided by the insurers so much that it leads to higher HMO prices, as HMOs 'shadow-price' the insurers, taking advantage of the increase in their market power that results from the higher price of 
the substitute product. At some intermediate levels of competitiveness in the insurance industry, the market segmentation effect may prevail in the insurance market, while not being strong enough to outweigh the direct competitive effect in the HMO market. In this case, increased HMO competition may both increase insurance premiums through the market segmentation effect and decrease HMO premiums through the direct effect of increased competition. 


\section{Appendix B: Endogenous HMO Entry}

Figure $\mathrm{B} 1$ depicts an industry demand curve for HMO coverage (given $\mathrm{p}_{\mathrm{i}}^{*}$ and $\gamma_{1}$ ) and the associated Cournot equilibrium quantity $q_{c}\left(\gamma_{1}\right)$ for some number of firms $N_{h}$ (generating zero profits net of fixed entry costs). When $\gamma$ increases from $\gamma_{1}$ to $\gamma_{2}$, the demand curve flattens because $\partial \mathrm{B}^{\prime} / \partial \gamma<0$, which implies that demand elasticity rises at every price-quantity pair. However, the relative position of this flatter curve is not theoretically determined by our assumptions on the demand model. If the demand curve rotates through the existing equilibrium (as does $D\left(\gamma_{2}, p_{i}^{*}\right)$ in figure $\mathrm{B} 1$ ), so that penetration is unchanged at existing prices, then the increased demand elasticity implies that the new HMO industry-best-response will lie further to the right. However, increased demand elasticity necessarily lowers equilibrium prices, and the lower equilibrium insurance price $\mathrm{p}_{\mathrm{i}}^{+}<\mathrm{p}_{\mathrm{i}}{ }^{*}$ or $\mathrm{p}_{\mathrm{i}}{ }^{\prime}<\mathrm{p}_{\mathrm{i}}{ }^{*}$ leads to a lower HMO demand curve, depicted as $\mathrm{D}\left(\gamma_{2}, \mathrm{p}_{\mathrm{i}}{ }^{+}\right)$and $\mathrm{D}\left(\gamma_{2}, \mathrm{p}_{\mathrm{i}}{ }^{\prime}\right)$ in figure B1 (where $p_{i}^{\prime}$ is assumed to be less than $p_{i}^{+}$). If the equilibrium quantity given this new demand curve lies under the old demand curve, at $q_{c}^{10}\left(\gamma_{2}\right)$ with $p_{i}^{\prime}$ for example, industry profits have fallen, and some exit is induced. (Since the original Cournot equilibrium lay to the right of the industry profit-maximizing quantity, further increases in quantity along or below that demand curve lower industry profits.) This exit leads to less aggressive behavior by the remaining firms, mitigating price competition, pushing the equilibrium demand curve back up, and offsetting the declines in prices and profits. Importantly, this exit could lead to lower equilibrium $H M O$ penetration under $\gamma_{2}>\gamma_{1}$, even in a model consistent with the model of appendix A except that endogenous HMO entry/exit is allowed. However, if the insurers' price response is sufficiently weaker $\left(p_{i}^{*}\right.$ falls to $p_{i}>p_{i}^{\prime}$, for example), the new equilibrium (with $N_{h}$ firms) lies above $D\left(\gamma_{1}, p_{i}^{*}\right)$, at $q_{C}{ }^{\text {hi }}\left(\gamma_{2}\right)$ for example, industry profits may rise, inducing some entry, further lowering the equilibrium demand curve, and offsetting the increases in both price and penetration. As long as the insurers' price response is not too strong, a 
sufficiently large rotation of the demand curve through equilibrium prices leads to higher profits for a fixed number of HMOs. The strength of the insurers' price response depends on many factors, including the competitiveness of the insurance industry and the effect of $\gamma$ on inframarginal demand, i.e., whether insurance demand is shifted up or down at existing prices. We do not make any assumptions about this inframarginal effect of $\gamma$ on $B(\theta ; \gamma)$, but note only that our assumption that $d \phi^{*} / d \gamma>0$ is consistent with the endogeneity of HMO entry as long as the insurers' price response is not too strong. 


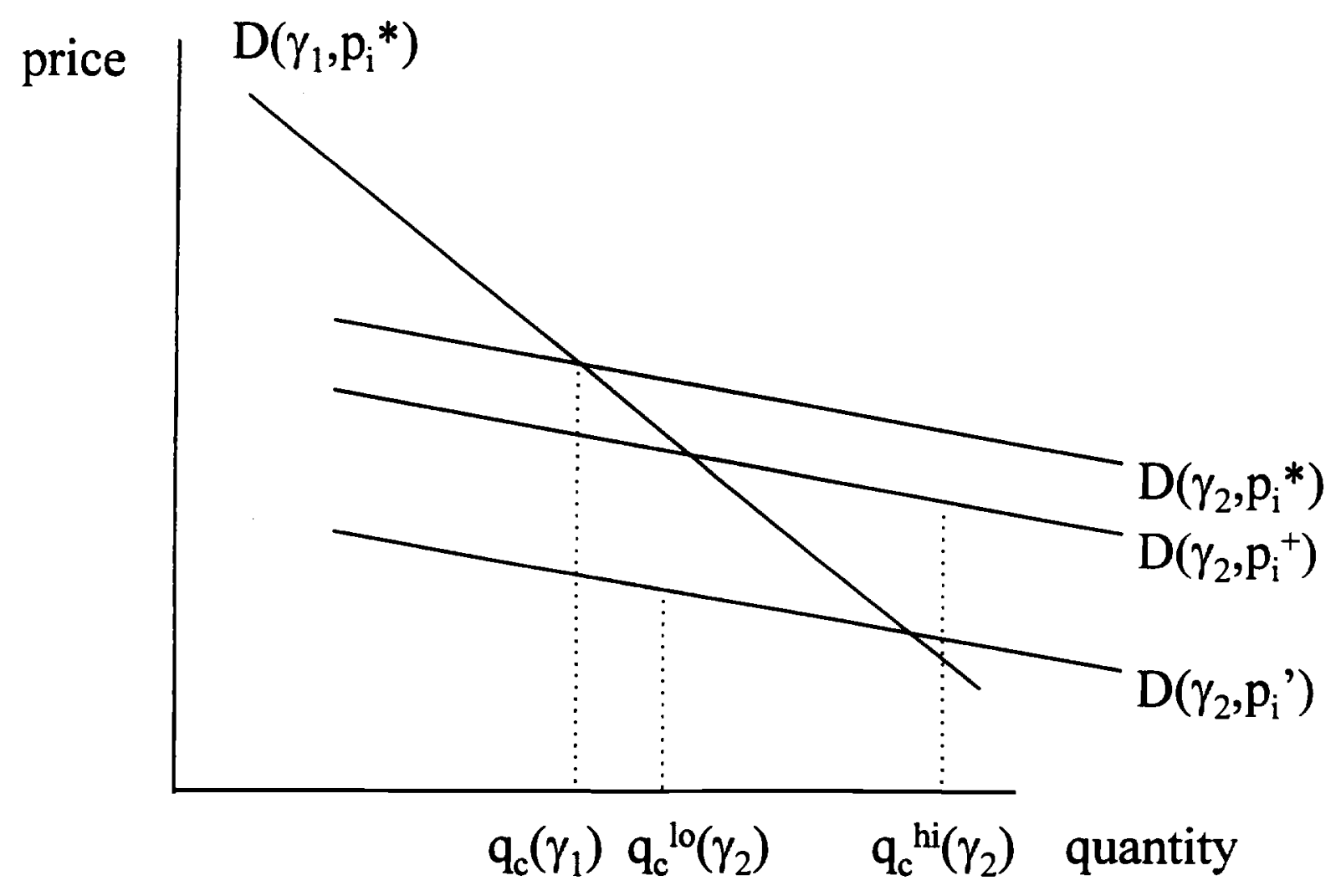

Figure B1 